\title{
The Whittard Canyon - a case study of submarine canyon processes
}

by

Amaro, T. ${ }^{*}$, Huvenne, V.A.I. ${ }^{2}$, Allcock, A.L. ${ }^{3}$, Aslam, T. ${ }^{4,5}$, Davies, J.S. ${ }^{6}$, Danovaro, R. ${ }^{7,8}$, De Stigter, H.C. ${ }^{9}$, Duineveld, G.C.A. ${ }^{9}$, Gambi, C. ${ }^{7}$, Gooday, A.J. ${ }^{2}$, Gunton, L.M. ${ }^{2}$, Hall, R. ${ }^{4}$, Howell, K.L. ${ }^{6}$, Ingels, J. ${ }^{10}$, Kiriakoulakis, K. ${ }^{11}$, Kershaw, C.E. ${ }^{11}$, Lavaleye, M.S.S. ${ }^{9}$, Robert, K. ${ }^{2}$, Stewart, H. ${ }^{12}$, Van Rooij, D. ${ }^{13}$, White, M. ${ }^{3}$, Wilson, A.M. ${ }^{3}$

*Corresponding author:

${ }^{1}$ Hellenic Center for Marine Research (HCMR), 71003 Heraklion, Crete, Greece.

${ }^{2}$ National Oceanography Centre, University of Southampton Waterfront Campus, Southampton, SO14 3ZH, UK.

${ }^{3}$ Ryan Institute and School of Natural Sciences, National University of Ireland, Galway, University Road, Galway, Ireland

${ }^{4}$ Centre for Ocean and Atmospheric Sciences, School of Environmental Sciences, University of East Anglia, Norwich, UK

${ }^{5}$ Centre for Environment Fisheries and Aquaculture Sciences (Cefas), Lowestoft, UK

${ }^{6}$ Marine Biology \& Ecology Research Centre, Marine Institute, Plymouth University, Plymouth, PL4 8AA, UK.

${ }^{7}$ Dep Life and Environmental Sciences, Polytechnic University of Marche, Ancona, Italy

${ }^{8}$ Stazione Zoologica Anton Dohrn, Villa Comunale I, Napoli, Italia

${ }^{9}$ NIOZ Royal Netherlands Institute for Sea Research, Department of Ocean Systems Sciences, and Utrecht University, PO Box 59, $1790 \mathrm{AB}$, Den Burg, Texel, The Netherlands.

${ }^{10}$ Plymouth Marine Laboratory, Prospect Place, West Hoe, PL1 3DH, Plymouth, UK

${ }^{11}$ School of Natural Sciences and Psychology, Liverpool John Moores University, Liverpool, L3, 3AF

${ }^{12}$ British Geological Survey, The Lyell Centre, Research Avenue South, Edinburgh EH9 3LA, UK.

${ }^{13}$ Renard Centre of Marine Geology (RCMG), Department of Geology and Soil Science, Ghent University, Krijgslaan 281 S8, B9000 Gent, Belgium 


\section{ABSTRACT}

Submarine canyons are large geomorphological features that incise continental shelves and slopes around the world. They are often suggested to be biodiversity and biomass hotspots, although there is no consensus about this in the literature. Nevertheless, many canyons do host diverse faunal communities but owing to our lack of understanding of the processes shaping and driving this diversity, appropriate management strategies have yet to be developed. Here, we integrate all the current knowledge of one single system, the Whittard Canyon (Celtic Margin, NE Atlantic), including the latest research on its geology, sedimentology, geomorphology, oceanography, ecology, and biodiversity in order to address this issue. The Whittard Canyon is an active system in terms of sediment transport. The net suspended sediment transport is mainly up-canyon causing sedimentary overflow in some upper canyon areas. Occasionally sediment gravity flow events do occur, some possibly the result of anthropogenic activity. However, the role of these intermittent gravity flows in transferring labile organic matter to the deeper regions of the canyon appears to be limited. More likely, any labile organic matter flushed downslope in this way becomes strongly diluted with bulk material and is therefore of little food value for benthic fauna. Instead, the fresh organic matter found in the Whittard Channel mainly arrives through vertical deposition and lateral transport of phytoplankton blooms that occur in the area during spring and summer. The response of the Whittard Canyon fauna to these processes is different in different groups. Foraminiferal abundances are higher in the upper parts of the canyon and on the slope than in the lower canyon. Meiofaunal abundances in the upper and middle part of the canyon are higher than on adjacent slopes, but lower in the deepest part. Mega- and macrofauna abundances are higher in the canyon compared with the adjacent slope and are higher in the eastern than the western branch. These faunal patterns reflect the fact that the Whittard Canyon encompasses considerable environmental heterogeneity, related to a combination of organic matter trapping, current regimes (due to focused internal tides) and different substrates. We conclude that coordinated observations of processes driving faunal patterns are needed at a fine scale in order to understand the functioning of communities in this and other submarine canyons. 


\section{INTRODUCTION}

More than 9450 large submarine canyons have been identified along the World's continental margins (Harris et al., 2011), making them important features that affect the geology, sedimentology, oceanography, biology and ecology of our oceans. Their presence gives rise to complex physical oceanographic conditions that locally enhance primary productivity and increase particulate matter concentrations (Bosley et al., 2004; Ryan et al., 2005; Skliris \& Denidi, 2006). They provide the main transport pathways between the shelf and the deep ocean, funnelling sediments, nutrients and organic matter (OM) (Puig et al., 2014) as well as pollutants and litter (e.g. Palanques et al., 2008; Pham et al., 2014) into the deep sea. These phenomena eventually lead to an enrichment in abundance and diversity of biological communities (Schlacher et al., 2007, Danovaro et al., 2009; Bianchelli et al., 2010; Vetter et al., 2010) including commercially important stocks of fish and shellfish (Puig et al., 2012). However, the processes controlling these phenomena are only partly understood. The interactions between oceanography, sediment transport, biogeochemistry and the resulting spatial distributions of biological communities are particularly unclear.

Submarine canyons, with their steep morphology, variable current speeds and occasional catastrophic flows, are challenging environments to study. Recent technological advances (e.g., the use of Remotely Operated Vehicles, gliders and robust landers) have driven an increase in the number and geographical spread of submarine canyon studies. However, a more complete picture of the processes acting and interacting in submarine canyon settings can only be obtained from concerted studies of individual canyons (Huvenne \& Davies, 2014). The aim of this overview is therefore to integrate current knowledge of processes operating in the Whittard Canyon, one of the main submarine canyons along the Celtic Margin, NE Atlantic.

The Whittard Canyon is an interesting case study for several reasons. Firstly, the canyon head is located approximately $300 \mathrm{~km}$ from land (Fig. 1). This means that terrestrial sediment input is strongly reduced compared to canyons receiving direct river input (e.g. Kaikoura Canyon, off the coast of New Zealand) or canyons that have their heads close to the shoreline and hence act as traps for along-shore sediment transport (e.g., Nazaré Canyon, Iberian Margin). Hence, from this perspective, this canyon may appear inactive (Toucanne et al., 2006). However, the Whittard Canyon 
still encompasses the complexities of a shelf-incising submarine canyon (as defined by Harris \& Whiteway, 2011): a dentritic morphology with multiple branches converging into a single deep-sea channel, topography (steep and vertical walls), rich and varied biological communities. Therefore, a broad range of typical canyon processes (e.g. internal waves, small-scale slope failures, sediment gravity flows, lateral transport, Allen \& Durrieu de Madron, 2009; Puig et al., 2014) are still acting here and can be studied without being obscured by repeated throughputs of terrestrially-derived material. The Whittard Canyon has been the subject of a wide range of specific studies over the past 10-15 years, covering many aspects of submarine canyon research. By combining all the available data and insights obtained by these individual investigations (Table 1), we aim to advance our understanding, not only of the Whittard Canyon system as a whole but also of canyon processes in general. As a framework for this integration, this paper will tackle the following questions. 1) Is the Whittard Canyon active in terms of sediment transport? 2) If so, at which temporal and spatial scale? 3) What impact does this (in)activity have on the associated benthic fauna and their functioning?

\section{SETTING}

a) Geology of the Celtic Margin

The Celtic Margin is a WNW-ESE oriented passive margin that extends from the Goban Spur to the Berthois Spur in the Bay of Biscay (Fig. 1). The adjacent continental shelf is wide, whereas its continental slope is steep (average slope $8^{\circ}$ ). The entire margin is cut by approximately 35 submarine canyons, with the Whittard Canyon being the most westerly located (Bourillet et al., 2006; Mulder et al., 2012). The Celtic spurs and canyons are associated with submarine drainage basins (Grande Sole and Petite Sole), and feed the deep-sea Celtic fan through the Whittard and Shamrock Canyons (Bourillet et al., 2006). During the last glacial period, they were connected to an active palaeovalley system (Bourillet et al., 2003; Toucanne et al., 2008), but its activity is now much reduced due to its distance from the present-day shoreline (Reid and Hamilton, 1990). The canyon morphology was influenced by existing NNW-SSE trending fault systems, older buried canyons and natural depressions in the seafloor (Cunningham et al., 2005). 
The Whittard Canyon is a deeply incising dendritic system, formed through headward erosion and retrogressive slope failure, starting in the Plio-Pleistocene, cutting deeply into Plio-Pleistocene aggradation and shelfal deposits, Miocene deltaic deposits (Fig. 2; Little Sole, Cockburn and Jones formations; Bourillet et al., 2003; Stewart et al., 2014) and the Cretaceous/Paleocene chalks (Evans, 1984; Cunningham et al., 2005). The most recent phase of canyon incision into the continental slope commenced during a number of episodic sea level lowstands in Plio-Pleistocene times (Fig. 2; Bourillet etal., 2003; Evans, 1990; Evans and Hughes, 1984). Fluvial connections to the Grande Sole and the Petite Sole drainage basins were via the Celtic Sea and Fleuve Manche respectively, resulting in multiple sediment sources for the Celtic deep-sea fan (Bourillet et al., 2003). Massive deglaciation of the British and European ice-sheets (ca. 20-13 ka) resulted in a significant increase in the fluvial flux to the Grande Sole drainage basin, and hence the Whittard Canyon, with terrigenous input prolonged until 7000 years ago by glacio-hydroisostatic uplift of the British Isles (Bourillet et al., 2003; Lambeck, 1996). The linear tidal sand ridges that developed on the outer continental shelf of the Celtic Sea (Praeg et al., 2015) between 20 and 12 ka years ago (Scourse et al., 2009) are also proposed as a sediment source to the Celtic deep-sea fan through strong tidal transport of sediments into the canyon heads (Bourillet et al., 2006; Scourse et al., 2009). However, recent current measurements and oceanographic modelling results suggest an opposite sediment transport direction (see below, and also in Cunningham et al., 2005).

The Whittard Canyon system has four main V-shaped branches (Fig. 1), which connect with the broad shelf at approximately $200 \mathrm{~m}$ water depth and merge at 3500 $m$ into the wide flat-bottomed or U-shaped Whittard Channel, that flows out to the Celtic Fan at 4500 m depth (Reid and Hamilton, 1990; Cunningham et al., 2005). The orientation of the canyon branches at the shelf edge is predominantly NNW-SSE and NNE-SSW (Cunningham et al., 2005). The canyon slope angles may increase to $40^{\circ}$ within the canyon heads and flanks, or possibly steeper, featuring steep cliffs and overhangs (Huvenne et al., 2011; Robert et al., 2015; Stewart et al., 2014). Typically, the upper flanks have complicated gully networks and numerous headwall scars from slumps and slope failures, which caused gravity driven flows that widened the canyon by retrogressive canyon wall failure. The seabed substratum is generally coarsegrained or mixed on the interfluves, whereas towards the flanks, the sediment becomes muddy, but with outcropping rocks within gullies or scars (Cunningham et 
al., 2005; Stewart et al., 2014). Additionally, Stewart et al. (2014) reported small mounds built of dead cold-water coral fragments on the Explorer and Dangeard interfluves (Eastern branches). In contrast to the morphologically diverse canyon walls, the canyon thalwegs are predominantly characterized by flat areas of soft sediment (Robert et al., 2015).

\section{b) Oceanography of the Celtic Margin}

The structure of the upper-water column $(1500 \mathrm{~m})$ along the Celtic Margin is characterised by central and intermediate water masses originating from sub-tropical latitudes. Relatively warm and saline Eastern North Atlantic Water(ENAW), a winter mode water with a source in the SW Bay of Biscay region, occupies the layer above the permanent thermocline (e.g. Perez et al., 1995; Pollard et al., 1996) with Mediterranean Outflow Water (MOW) present below the ENAW (e.g. van Aken, 2000; Van Rooij et al., 2010a). Flow characteristics are dominated by the European Slope Current (ESC) carrying ENAW (Pingree and Le Cann, 1990; Xu et al., 2015), and boundary flows associated with the MOW (Van Rooij et al., 2010a). The ESC is typically directed northwest (poleward) with mean flow speeds of $0.05-0.1 \mathrm{~ms}^{-1}$ (Pingree and LeCann, 1989; 1990) and varies seasonally, with a minimum in the principal driving mechanism during the summer months (Xu et al., 2015). Spring and autumn loss of slope-current continuity in the Whittard and Goban Spur region, through slope-ocean exchange and mean current reversals, has been reported and termed the SOMA (Sept-Oct-March-Apr) response (Pingree et al., 1999). Near the seabed, observed currents generally have a tidally induced downslope mean component balanced by Stoke transports (Pingree and LeCann, 1989). The possibility of cascading cold dense water from the shelf edge in winter and early spring was reported by Cooper and Vaux (1949), but has not subsequently been observed. In deeper adjacent waters, significant mesoscale variability exists within the MOW boundary flow and deeper (1600-2200 m) Labrador Sea Water layers (Bower et al., 2002).

Along the Celtic Sea shelf edge, internal waves and tides are generated at the shelf break by across-slope tidal flow (Pingree and Mardell, 1985; Holt and Thorpe, 1997). However, the direction of the propagating internal waves onto the shelf is quite random (Holt and Thorpe, 1997), in contradiction to the generally accepted view that across-shelf internal wave energy flux is controlled by the orientation of the shelf 
break (Garrett and Kunze, 2007). This is likely due to the highly corrugated nature (e.g. Nash et al., 2004) of the Celtic Sea shelf edge. Understanding the effect of the Whittard Canyon on the internal wave field is therefore important in understanding the internal wave dynamics within the larger Celtic Sea region. The semi-diurnal tide has been observed to drive $28-48 \mathrm{~W} \mathrm{~m}^{-1}$ of energy on-shelf (Hopkins et al., 2014), with the positive on-shelf energy flux modulated by nonlinear interaction between the vertical velocity associated with the semi-diurnal internal tide, and the vertical shear of inertial oscillations, leading to an increase of $25-43 \%$ in the energy flux. Internal solitary waves with amplitudes reaching a maximum of $105 \mathrm{~m}$ have also been reported (Vlasenko et al., 2014). The internal tide generated at the shelf break has been observed as a coherent signal up to $170 \mathrm{~km}$ onto the Celtic Sea shelf (Inall et al., 2011). However, an estimated shoreward energy decay scale of $42 \mathrm{~km}$ implies that much of the energy generated at the shelf edge is dissipated at or near the shelf break.

Primary productivity along the Celtic Sea margin is reasonably high, with estimates between 100-250 $\mathrm{g} \mathrm{C} \mathrm{m}^{-2} \mathrm{yr}^{-1}$ reported (Joint et al., 1986; Rees et al., 1999; Wollast and Chou, 2001). Near the Whittard region, Wollast and Chou (2001) report a value of $200 \mathrm{~g} \mathrm{C} \mathrm{m}^{-2} \mathrm{yr}^{-1}$ decreasing to $140 \mathrm{~g} \mathrm{C} \mathrm{m}^{-2} \mathrm{yr}^{-1}$ in deeper water $150 \mathrm{~km}$ from the shelf edge, with potentially $30 \mathrm{~g} \mathrm{C} \mathrm{m}^{-2} \mathrm{yr}^{-1}$ exported to the open slope and deep ocean. Mixing by internal tides at the shelf edge is recognised as a significant driver of nutrient fluxes and fuelling enhanced primary productivity (e.g. Holligan et al., 1985; Sharples, 2007). Sharples et al. (2007) found a spring-neap modulation in vertical nitrate fluxes across the seasonal thermocline. Neap tide fluxes were sufficient to sustain significant new production, but a 3-6 increase in fluxes at spring tide provided excess available nitrate.

\section{b.1) Surface tides}

Tides play an important role in submarine canyons, leading to rectified barotropic flows, enhanced currents and mixing (Allen and Durrieu de Madron, 2009). Measurements of the barotropic tide close to Whittard Canyon $\left(48^{\circ}\right.$ $34.59^{\prime} \mathrm{N}, 9^{\circ} 30.69^{\prime} \mathrm{W}$ ) over a spring-neap cycle show a variable depth-mean tidal current regime, $0.2 \mathrm{~m} \mathrm{~s}^{-1}$ during neap and $0.5 \mathrm{~m} \mathrm{~s}^{-1}$ during spring (Sharples et al., 2007). The semi-major axis of the depth-mean tidal flow is aligned approximately perpendicular (NE-SW) to the orientation of the isobaths at the sampling location and is confirmed by the TPXO 7.1 inverse model (Egbert, 1997; Egbert 
and Erofeeva, 2002). This across-slope alignment facilitates internal tide generation at the shelf edge and the upper reaches of the Whittard Canyon. In the Celtic Sea region, about $90 \%$ of the total kinetic energy of currents is contained in semi-diurnal frequencies, of which $75 \%$ can be attributed to the principal lunar semi-diurnal component $\left(\mathrm{M}_{2}\right)$ (Pingree, 1980). This distribution of tidal energy is also applicable to the Whittard Canyon.

\section{b.2) Internal tides}

The complex sloping topography associated with submarine canyons can result in both the generation and reflection of internal waves and tides (Hickey, 1995). Scattering of barotropic (surface) tides from the sloping topography can generate baroclinic (internal) tides (Baines, 1982), whilst reflection of existing internal waves can lead to trapping and focusing of internal wave energy from outside the canyon (Gordon and Marshall, 1976; Hotchkiss and Wunsch, 1982). The type of reflection that occurs can be predicted from the topographic slope gradient $\left(S_{\text {topog }}\right)$ and the internal wave characteristic slope gradient $\left(S_{\text {wave }}\right)$, the latter dependant on local stratification, internal wave frequency and latitude (Thorpe, 2005). Steep canyon walls typically cause supercritical reflection $\left(S_{\text {topog }} / S_{\text {wave }}>1\right)$ resulting in internal waves above the canyon rim being focused towards the canyon floor. Gently sloping canyon floors typically cause subcritical reflection $(<1)$ resulting in offshore internal waves being focused toward the canyon head. During both types of reflection, the separation between adjacent internal wave characteristics narrows, focusing the wave energy into a smaller volume and hence increasing energy density. In the case of near-critical reflection $(\cong 1)$, the energy is trapped against the boundary resulting in nonlinear effects such as wave breaking, internal bores and turbulent mixing (e.g. Nash et al., 2004).

Initial high-resolution simulations of the $\mathrm{M}_{2}$ tide in Whittard Canyon using a modified version of the Princeton Ocean Model (as used by Hall and Carter, 2011 and Hall et al., 2013 for Monterey Canyon) show that the depth-integrated baroclinic energy flux within the canyon is elevated, but variable in different branches (Fig. 3a) and that there is a significant flux from certain canyon branches onto the shelf. Enhancement of near-bottom tidal currents is also seen within the canyon (Fig. 3c), with peak velocities $>0.4 \mathrm{~m} \mathrm{~s}^{-1}$ in the upper reaches, 
and the current ellipses highly rectilinear along the canyon axes. In the lower reaches, current velocities are lower, around $0.1 \mathrm{~m} \mathrm{~s}^{-1}$, and the current ellipses more circular. Enhanced tidal currents and breaking internal waves within the canyon drive turbulent mixing, both in the bottom boundary layer and the interior of the water column. Elevated bottom boundary layer mixing may increase sediment and $\mathrm{OM}$ resuspension and along-canyon transport, potentially generate nepheloid layers, and has implications for benthic biology and ecology. Meanwhile, elevated interior mixing has the potential to enhance nutrient fluxes over the canyon, helping to fuel the enhanced primary productivity observed at the Celtic Sea margin.

\section{CANYON ACTIVITY}

\section{a) Nepheloid layers}

Nepheloid layers are cloudy layers of suspended particulate material largely driven by energetic hydrodynamics. They induce high turbidity compared to the surrounding clear waters contributing significantly to the shelf edge exchange of sediment (Mc Cave, 1986; Amin and Huthnance, 1999). They serve as a physical link between productive shallow environments and the deep abyss (Puig and Palanques, 1998), transporting biogenic and lithogenic material, supporting unique benthic ecosystems and contributing to the deposition of carbon in marine sediments.

Benthic (BNL) and intermediate nepheloid layers (INL) line the branches of the Whittard Canyon (de Stigter et al., 2008a; Huvenne et al., 2011; Wilson et al., 2015a). Wilson et al. (2015a) report INLs that occur at depths where the benthic source could be attributed to enhanced seabed currents, particularly associated with near-critical internal wave reflection, or the presence of the permanent thermocline, and at depths where MOW cores impinge on the slope (e.g. Van Rooij et al., 2010a). Locations of INLs sourced at the seabed in four branches of Whittard Canyon based on observations from four consecutive surveys (2011-2014) are highlighted in Fig. 3b. Extensive BNLs cover the upper reaches of the branches down to $2500 \mathrm{~m}$, likely maintained by canyon-enhanced near-bottom tidal currents (Fig. 3c). Intermittent INL observations in some of the branches of the Whittard Canyon (INLs observed in one survey only) may possibly be related to lower internal tide energy fluxes (Fig. 3 b). 
b) Current dynamics and tidally driven sediment transport

Near bottom current dynamics, in combination with temperature, salinity, turbidity and sediment flux, were recorded at various locations within the Whittard Canyon and Channel using the BOBO (BOttom BOundary; van Weering et al., 2000) and ALBEX (Duineveld et al., 2004) benthic landers. A number of deployments were carried out between 2007 and 2012 and lasted from a few days up to an entire year (Fig. 1). The lander records show that in the upper canyon reaches, extending from the shelf edge to about $2500 \mathrm{~m}$ depth, the near-bed current regime is indeed dominated by moderate to strong semi-diurnal tidal currents, flowing alternately in up- and down-canyon direction. Bottom water turbidity is generally observed to increase during periods of enhanced current speed, indicating that bottom sediment is resuspended and entrained by the tidal current (Fig. 4). Instantaneous horizontal particulate fluxes, calculated by multiplying suspended sediment concentrations with instantaneous current speed, reached values in the order of several grams $\mathrm{m}^{-2} \mathrm{~s}^{-1}$ during tidal current peaks. Net suspended sediment transport driven by tidal currents appeared to be generally in up-canyon direction, supporting the oceanographic modelling results (Fig. 4). At greater depths in the canyon (deployments at 3566 and $3569 \mathrm{~m})$ and in the adjacent deep-sea channel (4166 m), semi-diurnal tidal currents appear very weak, not exceeding $0.1-0.15 \mathrm{~m} \mathrm{~s}^{-1}$ and with no sign of resuspension of bottom sediment (Amaro et al., 2015). As also observed at shallower sites, net water flow at deeper sites was in an up-canyon direction, once more indicating that tidal currents do not contribute to down-canyon sediment transport (Mulder et al., 2012, Amaro et al., 2015). Low current speeds in the lower reaches of the canyon and the adjacent deep-sea fan area have previously been reported from short-term current meter deployments by Reid and Hamilton (1990).

\section{c) Recent sediment gravity transport}

Apart from the prevailing tidal currents, the BOBO landers deployed at 1479 and $4166 \mathrm{~m}$ recorded several events of significant down-canyon suspended sediment transport, which we interpret as representing sediment gravity flows (Fig. 4, Amaro et al., 2015). Typically, these events were marked by a sharp increase in suspended particulate matter (SPM) concentration, followed by a gradual decrease to normal values in the course of several days. Sediment trap samples encompassing these 
particular events recorded elevated sediment fluxes. In some cases the initial sharp increase in SPM was also accompanied by a marked increase in current speed and change to down-canyon flow. As illustrated by the 10-month BOBO record obtained at $1479 \mathrm{~m}$ depth in the western branch of Whittard Canyon (Fig. 4), sediment gravity flows occurring in the upper canyon reaches may be masked by the overall high concentrations of SPM and high current speeds. On several occasions the current speed at $1 \mathrm{~m}$ above bottom exceeded $0.7 \mathrm{~m} \mathrm{~s}^{-1}$. Two high current speed events, however, recorded on 15 November 2009 and 14 January 2010, showed characteristics of a sediment gravity flow. During the most intense event in January 2010, the instantaneous near-bottom sediment flux during the peak of the event was estimated to be in excess of $3.2 \times 10^{6} \mathrm{~kg} \mathrm{~m}^{-2} \mathrm{y}^{-1}$ in down-canyon direction. For comparison, the typical average rate of sediment accumulation at that depth as determined from ${ }^{210} \mathrm{~Pb}$ in sediment cores is in the order of $10 \mathrm{~kg} \mathrm{~m}^{-2} \mathrm{y}^{-1}$. During the last recorded high current speed event on 19 July 2010, probably representing another sediment gravity flow, the lander was dislodged from its anchors and was later recovered drifting at the surface.

In the more quiescent lower canyon, where background suspended matter concentrations is very low, the turbidity peaks representing sediment gravity flows were obvious. In a 12-month record obtained from $4166 \mathrm{~m}$ depth in the Whittard Channel, two sediment gravity flow events were recorded on $22^{\text {nd }}$ March and $1^{\text {st }}$ July 2011, marked by sharp increases in bottom water turbidity together with a strong increase in sediment deposition (Amaro et al., 2015). Very similar high-turbidity events also accompanied by high mass sediment flux have been reported from other canyon systems considered to be active (e.g. Xu et al., 2002; de Stigter et al., 2007; Martín et al., 2011). In the Whittard Canyon, storm depressions, common over the Bay of Biscay, may be the most likely trigger for these events, comparable to processes observed in other canyons (e.g. Martín et al., 2011; Sanchez-Vidal et al., 2012).

d) Recent sediment deposition

Surface sediments from major branches of the Whittard Canyon (western and eastern middle branch) and from the Whittard Channel, as well as from adjacent slope and interfluve areas, were studied in boxcores and multicores collected between 2007 and 2011 (Fig. 1). Sediments from the upper reaches of the western and eastern 
central branches and from the adjacent upper slope, down to depths of about $500 \mathrm{~m}$, appeared very similar, consisting of structureless silty sand composed for three quarters of lithogenic material (Fig. 5) and about one quarter of $\mathrm{CaCO}_{3}$. Toward greater depths, sediments on the slope adjacent to the western canyon branch become progressively depleted in lithogenic material, whilst $\mathrm{CaCO}_{3}$ content increases until constituting more than half of bulk sediment at depths below $3000 \mathrm{~m}$ on the lower slope. Most likely the observed trend reflects a decreasing input of lithogenic material with increasing distance from the shelf edge. In contrast to this, along the axis of the western and eastern middle canyon branches, lithogenic fine sand and silt consistently constitute the dominant sediment component down to $4000 \mathrm{~m}$ depth, suggesting ongoing transport of shelf-derived material down to the lower canyon reaches. On the interfluve adjacent to the eastern middle branch, lithogenic contents are also relatively high, possibly indicating sediment spillover from the adjacent canyon branches. Beyond $4000 \mathrm{~m}$ depth, where the lower canyon extends into the Whittard Channel, lithogenic fine sand and silt occurs as thin layers of a few mm thick, alternating with more carbonate-rich hemipelagic ooze. This indicates that down-canyon transport occurs episodically by sediment gravity flows, punctuating prolonged intervals of hemipelagic deposition. Sediment dating with ${ }^{210} \mathrm{~Pb}$ in a core from the proximal Whittard Channel showed that a number of these turbiditic layers were deposited within the last century. Thin turbidite layers were also observed in surface sediments draping the low banks to the east of the Whittard Channel, indicating spillover of turbidity currents from the main channel (Amaro et al., 2015). The fact that sediments on both sides of Whittard Channel contain distinctly more lithogenic material than lower slope sediments from west of the Whittard Canyon is another indication that spillover of turbidity currents contributes significantly to sediment deposition beyond the bounds of Whittard Channel. Apart from the afore-mentioned thin-bedded turbidites, one core from 4392 m depth in Whittard Channel contained a coarse sandy turbidite layer and debris flow deposit, in which abundant fragments of scleractinian corals were found. These corals must have been transported from the upper reaches of the canyon and slope at 250-2000 m depth, where both living and dead corals have been reported from ROV and towed video frame explorations (van Rooij et al., 2010a, Huvenne et al., 2011, Johnson et al. 2013, Davies et al., 2014).

e) Organic matter $(\mathrm{OM})$ 


\section{e.1. Suspended Particulate Organic Matter (sPOM)}

Huvenne et al. (2011) showed that near bottom ( $<10 \mathrm{~m}$ altitude) sPOM concentrations, measured using stand-alone pumps (SAPS - Challenger Oceanic), were 2 to 3 times higher in the upper parts of the canyon $(<2000 \mathrm{~m}$ depth) than in the deeper and more central parts (three stations > $3000 \mathrm{~m}$ depth). These values were comparable to those found in canyons from the Iberian Margin (Tyler et al., 2009; Kiriakoulakis et al., 2011). The observed decrease in sPOM concentrations with water depth was attributed to the less dynamic nature of deeper parts of the canyon. SPOM appeared to be fresh and phytoplankton-derived as suggested by the low molar $\mathrm{C} / \mathrm{N}$ ratios $(4.1$ - 7.7). In addition, they showed that the nutritional quality of SPOM was higher in the upper canyon, as illustrated by the elevated concentrations of essential fatty acids, docosahexaenoic fatty acid (DHA) and eicosapentaenoic fatty acid (EPA). EPA and DHA are biosynthesized primarily by phytoplankton and are pivotal in aquatic ecosystem functioning, as they greatly affect trophic transfer efficiency to higher trophic levels (Muller-Navarra et al., 2004; Kiriakoulakis et al., 2004, 2011).

Recently Wilson et al. (2015b) also investigated the SPOM in the intermediate and bottom nepheloid layers in the central upper branches of the Whittard Canyon. Data were collected in early summer 2013, mainly by filtering water from CTDs and to a lesser extent, from SAPS. Peaks in turbidity were detected with unusually high concentrations of SPM, in some cases greater than an order of magnitude higher than maximum values typically found in NLs. SPOM from these nepheloid layers was strikingly different from that reported by Huvenne et al. (2011) both in concentration and elemental composition. The suspended particulate organic carbon (sPOC) concentrations were more than an order of magnitude higher in the Wilson study (up to $690 \mu \mathrm{g} \mathrm{L}^{-1}$; vs. $12-23 \mu \mathrm{g} \mathrm{L}^{-1}$ in similar canyon depths), indicating that an episodic event had possibly taken place. The molar $\mathrm{C} / \mathrm{N}$ ratios of the sPOM from these NLs were highly variable, ranging from 1 to 27 . Although care needs to be exercised in comparing data from different sampling techniques (i.e. SAPS vs CTDs; see Turnewitsch et al. 2007). The results clearly show that sPOM collected during this study was highly heterogeneous, with possible contributions from clay-trapped inorganic nitrogen, bacteria and zooplankton (see references in Kiriakoulakis et al. 2011) and degraded material ( $\mathrm{C} / \mathrm{N}$ ratios above 10 indicate degraded $\mathrm{OM}$ in the absence of terrestrial inputs) in comparison to Huvenne et al. (2011). It is interpreted that these NL are possibly influenced by bottom trawling (see section 5). 
A further insight on OM fluxes in the canyon system was provided by Amaro et al. (2015) based on the sediment trap record obtained from a one-year lander deployment at $4166 \mathrm{~m}$ depth in the Whittard Channel. Sediment traps provide a time series of particle fluxes suitable for investigating sinking material (White et al., 2015). The study by Amaro et al. (2015) concluded that the highest flux of fresh OM arriving in the Whittard Channel was due to local vertical settling and lateral transport of phytodetritus, after the spring phytoplankton bloom, rather than through gravitydriven episodic events, which provided material of low nutritional quality.

\section{e.2. Sedimentary organic matter (SOM)}

Canyons may act as 'traps' of organic matter (OM) as has been observed in the Nazaré Canyon off the coast of Portugal (e.g. Masson et al., 2010). The high sedimentation rates in Nazaré Canyon promote carbon burial by reducing the oxygen exposure time of the sediment (Kiriakoulakis et al., 2011). Evidence about the potential of other European canyons, such as the Whittard Canyon, to act as OM (and hence carbon) sinks can be derived from total organic carbon (TOC) contents and the elemental (i.e. C/N ratios; e.g. Meyers 1997) and molecular (e.g. Duineveld et al., 2001; Kiriakoulakis et al., 2011; Amaro et al., 2015) composition of OM in the sediment.

Duineveld et al. (2001) measured sedimentary TOC and total nitrogen (TN) content in the upper $5 \mathrm{~cm}$ at three stations in the middle-lower central branches of the Whittard Canyon (2735 - $4375 \mathrm{~m}$ water depth) and found that TOC (and TN) contents in the upper $\mathrm{cm}$ of the canyon sediments were double the values than at corresponding depths on the nearby open slope (Goban Spur). The shallowest station (2735 m) had highest overall TOC and TN content throughout the upper $5 \mathrm{~cm}$, whereas at the two deeper stations levels sharply dropped below 2-3 cm. Duineveld et al. (2001) attributed this drop in TOC and TN at the deeper stations to a subsurface layer of coarse sand most likely originating from a gravity flow event. In general, coarser grains increase oxygen exposure and thus oxidation of SOM (Hedges and Keil 1995).

Extensive surveys of SOM in surface sediments $(0-1 \mathrm{~cm})$ along the axes of the western and eastern middle branches of Whittard Canyon showed that TOC and TN content generally increases towards the deeper part $(\sim 4000 \mathrm{~m})$ of the canyon and decreases from the proximal to more distal areas of the Whittard Channel and adjacent deep-sea fan area (Fig. 6). This apparent increase of the TOC content in the 
deeper locations could be due to a corresponding decrease of the sediment particle size. However, no significant relationship was found between median grain size and TOC in cores from seven locations in the canyon axes of the upper middle branches, which were sectioned every $\mathrm{cm}$ down to $10 \mathrm{~cm}$ (Spearman's Test, $\mathrm{r}=0.450, \mathrm{p}=0.224$ ). Alternatively, the higher TOC contents in the lower canyon reaches and proximal part of the Whittard Channel could be explained by intermittent sediment gravity flows flushing fine-grained sediments enriched in SOM down the canyon. Less frequent occurrence of sediment gravity flows further down the Whittard Channel could then explain the decreasing OC contents towards more distal areas. However, in some locations within the Whittard Canyon (depths between 650 to $4450 \mathrm{~m}$ from eastern to western branches), surficial sediments are practically indistinguishable from open slope values at the same depth $(0.1-0.7 \%$ TOC of dry sediment) (Huvenne et al. (2011). TOC content presented in surface sediments and sediment traps (Fig. 6) from the Whittard Canyon branches in part supports the analyses presented by Amaro et al., (2015). This could be due to the complexity and spatial and temporal variability of the canyon processes that are as yet poorly understood.

As a crude measure of lability of SOM its molar $\mathrm{C} / \mathrm{N}$ ratios from various locations in and outside the Whittard Canyon has been investigated by several authors (Duineveld et al., 2001; Huvenne et al., 2011; Ingels et al., 2011; Amaro 2015; de Stigter et al., 2008b). Molar $\mathrm{C} / \mathrm{N}$ ratios of surface sediments show no consistent differences between canyon and slope sites, nor any consistent trends from the upper canyon and slope to the lower canyon and slope (Fig. 7). This, in combination with consistently low $\mathrm{C} / \mathrm{N}$ ratios, suggests that the bulk of the $\mathrm{OC}$ preserved in surface sediments is broadly of relatively unaltered marine origin (Meyers 1997 and reference therein). The TOC contents of particulate matter collected in sediment traps close to the seabed in the western and eastern middle branches were significantly higher than in the nearby surface sediments $(1.09 \pm 0.51$ and $0.47 \pm 0.20$ respectively; T-test, $\mathrm{p}<0.05$ ), while molar $\mathrm{C} / \mathrm{N}$ ratios were significantly (if only slightly and still indicating marine origin) lower $(8.12 \pm 1.23$ and $8.80 \pm 1.68$ respectively; T-test, $\mathrm{p}<0.05)$. It is unclear, however, whether the differences are due to modification of settling OM by benthic organisms, as suggested by Amaro et al., (2015), or by dispersal of slightly degraded OM from the shelf across the canyon and slope or a combination of both processes. 
Few studies have investigated phytopigments, nucleic and fatty acids (and hence the bioavailability of sedimentary organic matter) in the Whittard Canyon. Duineveld et al. (2001) showed that concentrations of phytopigments and nucleic acids decreased, both down slope and down core within the canyon, suggesting a lowering of $\mathrm{OM}$ bioavailability with canyon and core depth. In contrast to bulk sediment and TOC distributions and concurrent with the observations described for sPOM, there is not yet any evidence for systematic down-canyon transport of labile organic material. Whilst current meter and fluorometer data recorded with a benthic lander in the upper canyon indicate resuspension and transport of phytodetritus by oscillating tidal currents (Fig. 8), the net transport of resuspended material appears to be in up- rather than in down-canyon direction. Up-canyon transport of phytodetritus, as well as proximity to shelf surface production, may well contribute to the high phytopigment concentrations reported by Duros et al. (2011) from the upper canyon. Even where intermittent gravity flows have been recorded, such as in the proximal Whittard Channel (Amaro et al., 2015), their role in transferring labile OM to lower slope regions appears very limited. More likely, the labile organic material flushed down-canyon by gravity flows, becomes strongly diluted with bulk sediment entrained by the flow, rendering it of little value for consumption by fauna in the area of deposition. Gravity flows through the canyon occasionally detected in sediment traps, resulted in accumulation of low quality degraded material.

\section{FAUNAL ASSEMBLAGES}

\section{a) Foraminifera}

Most of the information on foraminifera in the Whittard Canyon and adjacent areas derives from the study of Duros et al. (2011), who analysed sediment samples obtained from 18 stations for benthic foraminifera (>150 $\mu \mathrm{m}$ fraction). (Fig.1, Table 1). Densities of Rose-Bengal stained foraminifera, indicating living specimens, were positively related to phytopigment concentrations and to proxies for food availability, leading to higher standing stocks in the upper parts of the canyon and on the slope than in the lower canyon (Duros et al., 2011). Many of these upper canyon stations (328-525 m, $1109 \mathrm{~m}$ ) were characterised by a dominance of species (notably Bolivina spp., Bulimina marginata, Cassidulina carinata, Trifarina angulosa and Uvigerina 
peregrina) that are typical for organically enriched settings. The deepest site (3002 m in the western branch) was dominated (62\% of fauna) by Quinqueloculina seminula. Agglutinated species (Reophax spp., Lagenammina difflugiformis) typical of tranquil deep-water environments are common together with Bulimina costata and B. inflata. At shallower sites (mainly $<600 \mathrm{~m}$ ) in both canyon branches, particularly the eastern branch, there was a strong concentration of stained foraminifera in the upper $0.5 \mathrm{~cm}$ sediment layer, reflecting the shallow oxygen penetration depth associated with a high $\mathrm{OM}$ input. At deeper sites, stained foraminifera followed oxygen in tending to penetrate further into the sediment. However, shallow-infaunal species, which typically occur in surficial sediment layers, were also encountered in deeper core layers, for example, at $515 \mathrm{~m}$ in the western branch and $328 \mathrm{~m}$ in the eastern middle branch. This is probably a result of bioturbation by macro- and mega-fauna.

Foraminiferal densities decreased with water depth on the slope adjacent to the eastern and western branches. Assemblage composition changed accordingly and was largely different from that observed in the canyon, particularly at shallower depths. Uvigerina mediterranea (considered to be an opportunistic species that responds to phytodetritus pulses) was dominant (48\%) at $498 \mathrm{~m}$ depth on the western slope, $U$. mediterranea, U. peregrina and Melonis barleeanum were abundant around $1000 \mathrm{~m}$ on both slopes, $U$. peregrina was joined by Hoeglundina elegans, Cibicidoides kullenbergi, Gavelinopsis translucens and Gyroidina orbicularis at 1500-2000 m, while the deepest slope sites $(2950-3000 \mathrm{~m})$ were characterised by species of Reophax, Lagenammina and Ammobaculites agglutinans. This sequence reflects increasingly food-depleted conditions with increasing water depth, as is typical on continental margins. The distribution of stained specimens within the sediment profile is more consistent with depth on the slope than in the canyon. However, as expected, sediment penetration still tended to be deeper at the deeper sites. Comparison between stained and dead assemblages reveals evidence for the transport of dead foraminiferal tests within the canyon (Duros et al., 2012). Species that are confined to the stained assemblage in the upper canyon are found as dead tests at deeper sites. In addition, the dead tests of species (Ammonia beccarii and Haynesina germanica) that are restricted to coastal settings occur at shallow (328 and $535 \mathrm{~m}$ ) sites in the eastern canyon branch. These have probably been carried into the upper canyon by bottom currents, gravity flows or transported on floating algae. Differences between stained and dead assemblages in the area of the Whittard Canyon can also reflect seasonal population 
fluctuations. Thus, Epistominella exigua, an opportunistic species that responds with rapid population growth to inputs of phytodetritus (Gooday, 1988), represents 13\% of the dead fauna, but only $2 \%$ of the living fauna collected at $2995 \mathrm{~m}$ on the western slope in June 2007 (Duros et al., 2012). Many of these dead tests are presumed to have been generated during a reproductive burst earlier in the year.

An earlier study by Weston (1985) provided species-level information on benthic foraminifera from the Whittard Canyon in a study that also encompassed the nearby Shamrock Canyon and Meriadzek Terrrace and the more tranquil environment of the Porcupine Seabight. Weston (1985) studied Rose Bengal-stained and dead assemblages $(>125-\mu \mathrm{m}$ fraction) in grab and anchor dredge samples collected at depths between $255 \mathrm{~m}$ and around $2000 \mathrm{~m}$ depth in the canyon. Standing stocks of stained tests were considerably higher in the Whittard Canyon than at comparable depths in the Porcupine Seabight and there were substantial differences in both the stained and dead faunas from the two areas. For example, certain species, notably Cassidulina carinata but also Trifarina angulosa, T. bradyi, Brizalina spathulata and B. subaenariensis, were considerably more abundant in the stained assemblage, and occurred at greater depths, in the Whittard Canyon than in the Porcupine Seabight. As a result, the latter area displayed a much clearer zonation of species with depth than the canyon. Many of the species reported by Weston from the Whittard Canyon are the same as those in Duros et al. $(2011,2012)$. However, she also records attached species (Cibicides lobatulus, C. refulgens, Planulina ariminensis, Paromalina crassa), not reported by Duros et al. (2011, 2012), living on various hard substrates (e.g. pebbles, ascidians, agglutinated foraminiferan tubes, sponge spicules) between 700 and $1400 \mathrm{~m}$ depth.

\section{b) Meiofauna}

Ingels et al. (2011a) reported meiofaunal abundance and biodiversity (as nematode genera) at two stations (ca. 700 and $1000 \mathrm{~m}$ depth), within the western middle branch of the Whittard Canyon. Data collected by Gambi and Danovaro (2016) between 1483 and $2939 \mathrm{~m}$ in the eastern middle branch have allowed to identify meiofaunal patterns along a wider bathymetric range in the middle branches of the Whittard canyon. To assess differences in terms of meiofaunal abundance and nematode diversity (as expected number of genera for 51 individuals) among the stations selected here, we used one-way permutational analyses of variance 
(PERMANOVA) under unrestricted permutation of raw data. The analyses were carried out using Station as 5 fixed levels (700m, 1000m, 1483m, 1938m, 2939m) and data of abundance and diversity were in three replicates. Significant terms were investigated using a posteriori pair-wise comparisons with the PERMANOVA $t$ statistic and 999 permutations. Because of the restricted number of unique permutations in the pairwise tests, $\mathrm{P}$ values were obtained from Monte Carlo samplings (Anderson and Robinson, 2003). The PERMANOVA analyses were performed using the routines included in the PRIMER6 \& Permanova software (Clarke and Gorley, 2006). The results of the statistical analyses reveal that meiofaunal abundance does not change between $700 \mathrm{~m}$ and $1938 \mathrm{~m}$ depth $(\mathrm{p}=0.287)$ while differences are observed between $700 \mathrm{~m}$ and $2939 \mathrm{~m}$ and between $1483 \mathrm{~m}$ and $2939 \mathrm{~m}(\mathrm{p}<0.05)$ and between $1000 \mathrm{~m}$ and $2939 \mathrm{~m}$ and between $1938 \mathrm{~m}$ and $2939 \mathrm{~m}$ ( $<<0.01$; Fig. 9a). Meiofaunal abundances in the upper and middle part of the Whittard Canyon are generally higher than those reported from the open slopes of the Atlantic Ocean (Celtic and Portuguese margins) and of the Mediterranean Sea (Catalan and South Adriatic margins) (Bianchelli et al., 2010; Ingels et al., 2009, 2011a, b, c, 2013a; Romano et al., 2013) at similar depths. Meiofaunal abundances at $3000 \mathrm{~m}$ depth in the Whittard Canyon are lower than values reported at comparable depths in Nazaré and Cascais Canyons along the Portuguese margin (Ingels et al. 2009, 2011b, c). Meiofaunal diversity (at the level of higher taxa) did not display a clear spatial pattern with increasing water depth (Fig. 9b). This lack of bathymetric pattern has been observed in several canyons, independent of geographical region or canyon-scale environmental conditions (Bianchelli et al., 2010; Ingels et al., 2013a; Romano et al., 2013; Leduc et al., 2014; Pusceddu et al., 2013) and is likely reminiscent of canyon heterogeneity and associated environmental variability exerting influence on benthic assemblages. More important are small-scale environmental conditions that act on the scale of meiofauna and nematodes, such as those associated with sediment grain size and sediment depth, or the amount and availability of food (Ingels et al., 2013b, Leduc et al., 2012, 2014b). Ingels et al. (2011) supported the former observation by showing that small-scale (vertical) heterogeneity in SOM quality (expressed mainly as relative contributions of phytopigments) within the same core could explain much of the variation of the meiofaunal communities of the canyon. In the middle branches of the Whittard Canyon fourteen meiofaunal taxa have been identified: Nematoda, Copepoda (including their nauplii), Polychaeta, 
Kinorhyncha, Bivalvia, Ostracoda, Turbellaria, Oligochaeta, Tardigrada, Gastrotricha, Isopoda, Tanaidacea, Acarina and Aplacophora. Meiofaunal community structure displays a typical composition of deep-sea assemblages with few dominant taxa: nematodes dominate (92-96\%) all stations, followed by copepods (3-7\%), kinorhynchs (0-3\%) and polychaetes (0-1\%). All other taxa can be considered as rare (sensu Bianchelli et al., 2010), since their contribution to the overall community composition is $<1 \%$, and their number displays a clear decreasing pattern at depth $>1000 \mathrm{~m}$. The results of the statistical analyses described above, reveal that, contrary to the spatial pattern observed for meiofaunal diversity in general, nematode diversity (as expected richness of genera for 51 individuals) decreases between $700 \mathrm{~m}$ and $1000 \mathrm{~m}$ ( $\mathrm{p}<0.05$ ), among 700m and all other sampling depths, expect for $1483 \mathrm{~m}$, and progressively decreases between $1483 \mathrm{~m}$ and $2939 \mathrm{~m}$ ( $\mathrm{p}<0.05)$, except for between $1939 \mathrm{~m}$ and 2939m (Fig. 10a). No differences in nematode diversity at species level (both as species richness and expected species number for 51 individuals) are observed between $1483 \mathrm{~m}$ and $2939 \mathrm{~m}$ in the middle eastern branch of the Whittard Canyon (Gambi and Danovaro, 2016). The present analysis of nematode assemblages in the middle branches of the Whittard Canyon reveals the presence of 119 nematode genera among a total of ca. 1400 individuals investigated from ca. 100 individuals from each of three replicate samples of each station. Ingels et al. (2011) reported the dominance of the genera Leptolaimus and Molgolaimus at $700 \mathrm{~m}$-depth and Astomonema at $1000 \mathrm{~m}$ depth, respectively while in the deepest stations the dominant genera are: Halalaimus (16\%), Acantholaimus (8\%) and Daptonema (6\%). Differences in genus dominance between the investigation by Gambi and Danovaro (2016), and Ingels et al. (2011a) are mostly caused by differences in bathymetric ranges considered in the two studies. These results are consistent with the patterns observed along other canyon systems and open slopes in which, the turnover of nematode genera (and species) is generally very high among sampling sites at greater water depths (Danovaro et al., 2009, 2014, Ingels et al., 2011, Gambi and Danovaro, 2016). Different drivers can be invoked to explain these patterns. Ingels et al (2011), indeed, revealed that the high variability of nematode genera composition was mainly explained by grain size and food availability (both quality and quantity) inside the canyon system. The analysis of nematode trophic structure at genus level does not display clear patterns along the bathymetric gradient in the middle branches of the Whittard Canyon (Fig.10b). Deposit feeders are always the dominant trophic guild, as 
observed for deep-sea sediments worldwide (Soetaert and Heip, 1995; Gambi et al., 2003; Vanhove et al., 2004; Danovaro et al., 2008; Vanreusel et al., 2010; Gambi et al., 2014). However, epistrate feeders contribute substantially to trophic composition at all stations and this could be related to the amount of "fresh" material in the canyon system deriving from the highly productive surface waters of the Celtic margin (Joint et al., 2001, Duros et al., 2011 and this manuscript). The relative contribution of predators is low and decreases progressively with increasing water depth. Predators represent a limited portion of the overall nematode trophic structure in the Whittard Canyon in comparison to their relevant contribution observed in the adjacent open slopes (Gambi and Danovaro, 2016) and in the oligotrophic sediments of the deep Mediterranean Sea (Danovaro et al., 2008, Gambi et al., 2014). Interesting to note is also the relatively high numbers of chemosynthetic Astomonema nematodes, particularly at $1000 \mathrm{~m}$ water depth, suggesting reduced sedimentary conditions akin to seep environments. These conditions may be caused by very high sedimentation rates and consequent enhanced respiration and organic carbon burial conditions, which allow these nematodes to thrive (Ingels et al., 2011a, Tchesunov et al., 2012). Such sedimentary conditions may be caused by sedimentary overflow on the interfluves of the canyon head.

c) Macrofauna

Duineveld et al. (2001) published the first study of macrofauna from the Whittard Canyon. Samples obtained at 2735 and 3760 m water depth yielded similar densities (2717 ind $\mathrm{m}^{-2}$ and 1339 ind $\mathrm{m}^{-2}$ ) to those found on the nearby Goban Spur, c. $150 \mathrm{~km}$ northeast of the canyon (3039 ind $\mathrm{m}^{-2}$ at $2200 \mathrm{~m}$ and 2420 ind $\mathrm{m}^{-2}$ at $3600 \mathrm{~m}$ ). The same was true for the sample taken on the canyon fan at $4375 \mathrm{~m}$ depth (canyon fan 696 ind $\mathrm{m}^{-2}$; Goban Spur 807 ind $\mathrm{m}^{-2}$ at $4500 \mathrm{~m}$ ) (Duineveld et al. 2001, Fig. 11). On the other hand, biomass values were elevated inside the canyon (4739, 1877 and $1592 \mathrm{mg} \mathrm{m}^{-2}$ wet weight at 2735, 3760 and 4375 water depth, respectively) compared with the Goban Spur $\left(3039,1256,886 \mathrm{mg} \mathrm{m}^{-2}\right.$ wet weight at 2200, 3600 and $4500 \mathrm{~m}$ water depth, respectively). This increase was consistent with higher levels of OM and pigments found in the surface sediments of the canyon compared with the slope.

In a recent study, Gunton et al. (2015b) compared macrofauna assemblages at $3500 \mathrm{~m}$ water depth in three different branches of the Whittard Canyon (Fig. 1) and the adjacent slope to the west of the canyon. The canyon had a higher macrofaunal 
density than the slope (canyon average $4536 \pm$ SD 1676 ind m ${ }^{-2}$; slope $2744 \pm$ SD 260 ind $\mathrm{m}^{-2}$ ). Density varied throughout the branches of the canyon, increasing across the sites from west to east (western branch $2900 \pm 538$ ind $\mathrm{m}^{-2}$; eastern middle branch $4461 \pm$ SD 856 ind $\mathrm{m}^{-2}$; eastern branch $6249 \pm \mathrm{SD} 1363$ ind $\mathrm{m}^{-2}$ ). This is consistent with the data of Hunter et al. (2013) who sampled macrofauna at a similar water depth $(3500 \mathrm{~m})$ in the canyon. They recorded higher macrofaunal densities in the eastern branch $\left(5352 \pm\right.$ SD 2583 ind $\left.\mathrm{m}^{-2}\right)$ compared with the western branch $(3416 \pm$ SD 2069 ind $\mathrm{m}^{-2}$ ) (Fig. 11). As seen in section 3, disturbance regimes and the quantity and quality of $\mathrm{OM}$ vary throughout the canyon branches and this may have led to the different faunal densities reported in both studies. However, as the stations analysed for the quantity and quality of $\mathrm{OM}$ (section 3) are different from those where macrofauna were sampled, we can only make assumptions and a more coordinated sampling programme should be carried out in the future, so that observations from all disciplines can be better integrated.

Gunton et al. (2015b) also found that the Whittard Canyon macrofauna exhibited considerable variability at the higher taxon level. Polychaeta was the dominant taxon at $3500 \mathrm{~m}$ and represented $>50 \%$ of the assemblage in the three main canyon branches. However, the ranking of the second and third most abundant taxa varied between branches and were respectively Sipunculida (12.5\%) and Bivalvia $(8.4 \%)$ in the western branch; Isopoda (16.2\%) and Tanaidacea (7.3\%) in the eastern middle branch; Isopoda (10.7\%) and Bivalvia (8.6\%) in the eastern branch. Hunter et al. (2013) also noted a difference in macrofaunal composition between canyon branches at $3500 \mathrm{~m}$. In the eastern branch macrofaunal-sized nematodes (> $50 \%$ ) and polychaetes (cirratulids and spionids) contributed most to the assemblage, whereas in the western branch crustaceans (tanaids and harpacticoid copepods) and polychaetes dominated. The differences between the two studies may reflect the sampling gear and sampling processing techniques used. Gunton et al. (2015b) used a megacorer and a $300 \mu \mathrm{m}$ sieve, whereas Hunter et al. (2013) used ROV push cores and a $250 \mu \mathrm{m}$ sieve. A megacorer will collect a larger sediment sample, while a larger sieve would retain fewer animals. Furthermore, Hunter et al. (2013) included nematodes in their macrofaunal analysis, but Gunton et al. (2015b) only included macrofauna sensu stricto. Polychaete family assemblage composition also varied throughout the canyon. Hunter et al. (2013) reported that the western branch had a high proportion of Amphinomidae, whereas Cirratulidae and Spionidae 
contributed most to the assemblage in the eastern branch. Gunton et al. (2015b) reported high numbers of Amphinomidae (all Paramphinome jeffreysii) in the western, central and eastern branches. The abundance of $P$. jeffreysii increased across sites from the western (21.2\%) to the eastern branch (39.6\%) (Gunton et al., 2015a). Aurospio sp. was ranked second in the western and eastern middle branches whereas juvenile Opheliidae were ranked second in the eastern branch. This within-canyon faunal heterogeneity is probably explained by a combination of variable organic enrichment and hydrodynamic activity, both of which can be influenced by the topographic profile of individual canyon branches (Gunton et al. 2015b and section 3 of this paper).

Although the macrofauna at all three stations in the study by Duineveld et al. (2001) were numerically dominated by deposit-feeders, the proportion of filterfeeders (mainly sabellid polychaetes) was highest at the deeper canyon station (3760 m). This was unexpected since more quiescent conditions, favouring deposit feeders rather than filter feeders, would normally be expected at greater depths. At slightly shallower depths $(3500 \mathrm{~m})$, polychaete feeding groups displayed a shift across the canyon, with a higher abundance of omnivores and macrophagous feeders reported in the eastern branch compared with more microphagous feeders in the western branch (L. Gunton unpublished observations). Macrofaunal-sized nematodes displayed a similar trend, the eastern branch was characterised by high numbers of predators and scavengers (e.g. Paramesacanthion) and the western branch by epigrowth feeders. Again, this shift in feeding groups may be linked to the different environmental characteristics of individual branches, as mentioned above.

Local macrofaunal diversity appears to be depressed inside the Whittard Canyon compared with the adjacent slope (Gunton et al., 2015a). Rarefied polychaete richness was similar in the western $\left(E\left[S_{47}\right]=18.5\right)$, eastern middle $\left(E\left[S_{47}\right]=19.9\right)$ and eastern $\left(E\left[S_{47}\right]=18.4\right)$ branches, but higher at the slope site to the west of the canyon $\left(E\left[S_{47}\right]=21.2\right)$. The Simpson $\left(1-\lambda^{\prime}\right)$ and Shannon $\left(H^{\prime}\left(\log _{2}\right)\right)$ indexes were likewise highest at the slope site $\left(1-\lambda^{\prime}=0.918, \mathrm{H}^{\prime}\left(\log _{2}\right)=4.104\right)$, intermediate in the western and eastern middle branches $\left(1-\lambda^{\prime}=0.880\right.$ and $0.856, \mathrm{H}^{\prime}\left(\log _{2}\right)=3.706$ and 3.891, respectively) and lowest in the eastern branch $\left(1-\lambda^{\prime}=0.814, \mathrm{H}^{\prime}\left(\log _{2}\right)=3.656\right)$. Dominance was also higher inside the canyon (Rank 1 dominance canyon average 33.1, slope 18.7). Depressed diversity and increased dominance may be caused by high numbers of opportunistic species. As mentioned above, P. jeffreysii and juvenile 
Opheliidae were particularly abundant in the eastern branch of the canyon, perhaps as a result of an opportunistic response to a possible recent input of OM. Forty-six polychaete species that were not present on the open slope, were found in the Whittard Canyon, suggesting that the canyon may enhance diversity at a regional scale (Gunton et al., 2015a). However, the sampling effort on the adjacent slope was not sufficient to confirm that the canyon acts to increase regional diversity.

d) Megafauna

Megafaunal abundances have been found to be higher in the eastern as opposed to the western branch of the Whittard Canyon, but species richness appears to be similar (Ismail et al. submitted). Only one Agassiz trawl sample is available from the Whittard Canyon. A single trawl at a similar depth $(3700 \mathrm{~m})$ on the Goban Spur in 1995, repeated in 1996, revealed only minor differences in overall megafauna density, biomass and indeed the distribution of feeding guilds on the open slope as compared to the Whittard Canyon (Duineveld et al., 2001). By combining visual (ROV) observations on megafauna with habitat characteristics in General Additive Models (GAMs), higher megafauna abundance in the Whittard Canyon was found at shallower depths $(<1000 \mathrm{~m})$, with small peaks at $\sim 2200$ and $3000 \mathrm{~m}$, while a peak in species richness occurred at $\sim 1200 \mathrm{~m}$ (Robert et al. 2015). Some of these peaks may be associated with the interface of water masses present within the region (van Aken, 2000a, b; section 2 of this paper). At a finer scale, increased abundance, species richness and diversity were associated with steep slopes and topographic highs, and decreased towards the thalweg (5). Video analysis of 17 transects $(500-4000 \mathrm{~m}$ in depth) identified $\sim 210$ morphospecies (5), of which 31 putative species were corals (based on 13 transects). The most commonly observed species in the outer branches of the Whittard Canyon were xenophyophores (probably Syringammina fragilissima), Pentametrocrinus sp., Acanella sp., Lophelia pertusa, cerianthids and Anthomastus sp. (Robert et al. 2015). Examination of beta diversity indicated a high species turnover with transects showing species similarities below 40\% (Robert et al. 2015), but many of these species have also been reported from other nearby banks, canyons and continental slopes, and are likely not to represent distinct communities (Tyler and Zibrowius 1992, Roberts et al. 2008, Howell 2010, Narayanaswamy et al. 2013, Davies et al. 2015). In terms of cold-water corals (CWC), the most abundant coral species found in a series of dive transects covering depths from $520-4703 \mathrm{~m}$ were 
Acanella sp., Anthomasthus sp. and L. pertusa (Morris et al., 2013). Although Morris et al. (2013) did not have a stratified random sampling scheme, the studied transects did cover a wide range of depths throughout the canyon and the coral distribution appeared to be driven by substratum type. The highest density of corals has been found along an overhanging vertical wall (1600 m long x $120 \mathrm{~m}$ high) at $1350 \mathrm{~m}$ water depth, mapped by Huvenne et al. (2011), where faunal coverage, mostly $L$. pertusa, was estimated at $\sim 70 \%$. Despite corals on vertical walls representing the habitat with the highest abundance and species richness, octocoral richness tended to be low (Morris et al. 2013, Robert et al. 2015). Species commonly found in this habitat included; the bivalve Acesta excavata, unidentified feather stars and an anemone species, possibly Actinauge sp. The frequently observed crinoids found in association with L. pertusa, (Robert et al., 2015) may represent a variant of the described ' $L$. pertusa and crinoids on bedrock' biotope as listed by Davies et al. (2014). At depths between 633-762 m, A. excavata was found to be highly abundant and form a different vertical-wall assemblage with the deep-sea oyster Neopycnodonte zibrowii (Johnson et al. 2013). Other commonly observed species found within this assemblage included the cup coral Desmophyllum dianthus, unidentified feather stars and unidentified pink cerianthids. Another smaller wall has been found in the western branch at $\sim 1650 \mathrm{~m}$, colonised by Primnoa sp. and possibly Solenosmilia variabilis (Huvenne et al., 2011). At the foot of these walls, high concentrations of SPM and the presence of bottom nepheloid layers have been recorded (Huvenne et al., 2011, Johnson et al., 2013). The potential increased mixing following the occurrence of down-canyon sediment gravity flows or the presence of internal waves (Wilson et al., 2015a) may explain why Lophelia within Whittard Canyon tend to occur outside the sigma-theta density envelope of $27.35-27.65 \mathrm{~kg} \mathrm{~m}^{-3}$ proposed by Dullo et al. (2008) and Flögel et al. (2014) for optimal Lophelia growth (Whittard Canyon coral wall: $\sim 27.80 \mathrm{~kg} \mathrm{~m}^{-3}$; Huvenne et al. 2011). Moreover and as mentioned in section 3, Huvenne et al. (2011) showed appreciable concentrations of essential fatty acids (EPA and DHA) in the surficial sediments from several areas of the upper and middle parts of the canyon, which can explain the presence of CWCs in the same areas. Protection against excessive sedimentation and increased food availability were suggested as potential drivers for the colonisation of vertical cliffs; cliff habitats may act as refuges from fishing activities, play a role in providing 
nursery habitats and protection against predation, and add complexity beneficial for other filter feeders (Huvenne et al. 2011, Johnson et al. 2013).

In the deepest part of the canyon (4166-4349 m) and in the Whittard Channel (4321-4448m), dense aggregations of elpidiid holothurians have been observed (Duineveld et al., 2001; Amaro et al., 2015). Since members of the Amperima/Peniagone species complex are among those deep-sea organisms that select the freshest type of phytodetritus (FitzGeorge-Balfour et al. 2010), their presence is most likely associated with favourable quantities of trophic resources (Amaro et al., 2010; Billett et al., 2010; Jamieson et al. 2011) and their high densities in areas like the Whittard Channel confirm the presence of highly valuable food for the rest of the deep-sea benthos. As discussed above, this fresh OM is most probably derived from vertical settling, transported by bottom currents from adjacent lower slope areas and trapped in the topographic depressions incised by the canyon and channel rather than being flushed down-canyon by gravity flows, which appear to dilute the organic matter with bulk sediment.

The Dangeard and Explorer canyons (SW Approaches) are shallower canyons which feed into the Whittard Canyon (Fig. 1; Stewart et al., 2014). Davies et al. (2014) identified and mapped 12 megabenthic assemblages (biotopes) from imagery data (acquired between 184-1059 m), which revealed that these canyons are dominated by soft sediment assemblages. Although no similar biotope analysis is available for the Whittard Canyon, dense sea pen aggregations (particularly Kophobelemnon) and Lophelia and/or Madrepora cold-water coral reef structures have also been observed between 400 and $1050 \mathrm{~m}$ water depth in the eastern middle branch (van Rooij et al., 2010a; ICES WGDEC 2012; Robert et al., 2014, Ingels et al., unpublished data). Kophobelemnon stelliferum has been recorded from the neighbouring Porcupine Seabight and so is not restricted to the canyons (Rice et al., 1992).

Many of the coral species observed in the Whittard Canyon have been also observed in the Dangeard and Explorer canyons including Acanella sp., Anthomasthus sp. and L. pertusa. Although CWC reef structures have been observed in the main branches of the Whittard Canyon, only one highly sedimented 'L. pertusa reef' $(795-940 \mathrm{~m})$ has been observed on a steep flute feature on the floor of Explorer Canyon. 
Interestingly areas of cold-water coral mini-mounds (up to $3 \mathrm{~m}$ high and 50$150 \mathrm{~m}$ in diameter) were found on the interfluves of Dangeard and Explorer canyons (250-410 m); but such features have not been recorded from the Whittard Canyon itself. Mini-mound provinces have also been recorded from the Guilvinec Canyon (2008, Armorican margin, De Mol et al., 2011) and between the Ferrol and A Coruña Canyon (van Rooij et al., 2009, Cantabrian margin, unpublished data) and so may be related to presence of the canyon, however mini-mounds have also been documented from the Porcupine Seabight upper slope (2003, Irish margin, Wilson et al., 2006),

\section{ANTHROPOGENIC INFLUENCES}

Recorded litter densities in Whittard Canyon are lower than in other nearby canyons of the same continental margin. Derelict fishing gear represents $\sim 28 \%$ of the observed litter suggesting anthropogenic impacts in this canyon system might be substantial, although in nearby Dangeard and Explorer Canyons this figure reached $72 \%$. Approximately $42 \%$ of the litter was plastic, which will degrade slowly (Pham et al. 2014).

For nearly a decade, the influence of anthropogenic activity (i.e. bottom trawling) on sediment transport has been highlighted in numerous studies in Mediterranean canyon systems (e.g. Martín et al., 2008; Puig et al., 2012; Martín et al., 2014). Recently, evidence has been presented suggesting that trawling similarly may influence SPM concentrations at the Whittard Canyon (Wilson et al., 2015b). ROV video survey footage (van Rooij et al., 2010c; Robert et al., 2015) has shown areas in the upper canyon (448-1119 m) that are draped by fine, loose sediment. This could suggest high rates of sedimentation and potentially overflow from sediment gravity events or tidal-driven sediment suspension, but could also be indicative of anthropogenic activity (i.e. bottom trawling). During a survey in 2013, concentrations of SPM in enhanced nepheloid layers (ENLs) were significantly higher (typical an order of magnitude) than the mean maximum in nepheloid layers normally observed in the Whittard Canyon (Wilson et al., 2015a). Wilson et al. (2015b) showed that vessel monitoring system (VMS) data indicated high spatial and temporal activity of trawling vessels coinciding with the occurrence of ENLs. Although only one study, the data would suggest that bottom trawling on the smooth adjacent spurs is triggering sediment gravity flows at the steeper rims of the canyon. The increased resuspended 
sediment induced by such activity maybe the cause of the episodic events detected by Amaro et al. (2015) and may explain the higher $\mathrm{C} / \mathrm{N}$ ratios of sPOM suggestive of degradation detected during the Wilson study in comparison to Huvenne et al., (2011). Episodic trawl-induced resuspension events could potentially have detrimental effects on local ecosystems, introducing high inorganic particle loading, which smothers filter feeders and provides nutritional unsuitable material (Puig et al., 2012).

\section{CONCLUSION AND FUTURE DIRECTIONS}

The following main conclusions emerge from the research results reviewed here.

1) The Whittard Canyon is currently still active in terms of sediment transport, although less so than during the last deglaciation. Intermediate and bottom nepheloid layers can be found throughout the (upper) canyon reaches, and benthic landers have recorded significant volumes of transported material, even in the deep Whittard Channel.

2) The net suspended sediment transport is mainly up-canyon, but sediment gravity flow events do occur (potentially due to anthropogenic activities) and carry shallowwater sediments and foraminiferal tests to greater depths. However, the down-canyon transport of labile OM by means of gravity flows appears to be limited. The fresh OM found in deeper regions, particularly the Whittard Channel, appears to arrive through the vertical deposition and lateral transport of settling phytodetritus from phytoplankton blooms that occur during spring and summer.

3) The active sediment transport and trapping of OM influences the benthic fauna. In general, meiofauna, macrofauna and foraminifera showed increased abundances and/or biomass inside the canyon compared to the continental slope (adjacent slope, Goban Spur or nearby Porcupine Seabight), although this pattern could not be conclusively demonstrated for the megafauna. Similarly meiofaunal and foraminiferal abundances were higher in the upper than in the lower canyon. These patterns are related to a local increase of OM, food availability or food quality in the canyon compared to on the slope and in the upper canyon compared to the lower cayon. Megabenthic filter feeders, such as sponges, anemones, crinoids and corals, are found 
in higher densities inside the canyon (especially on the walls) than on the open slope. They are higher in the eastern than in the western branch. A similar east-west pattern has been reported for macrofauna, and again appears to be linked to OM quality and quantity. There is no evidence for a contrast in megafaunal densities inside versus outside the canyon, although data are very limited to a single trawl sample and should be treated with caution.

4) Biodiversity patterns are less consistent than abundance patterns between faunal groups and seem more influenced by local effects within the canyon branches. Nematode diversity at genus level decreased progressively with increasing water depth in the western middle branch of the Whittard Canyon; this was not the case for meiofauna higher taxa diversity. Local macrofaunal diversity appeared to be depressed inside the Whittard Canyon compared to the adjacent slope, but was characterised by an increase in opportunistic species not seen on the slope. This suggests that the canyon may still enhance diversity at a regional scale and exert an important influence on macrofaunal abundance, biomass and diversity patterns both locally and regionally. The multiple patterns of biodiversity compared to the open slope are generated by the complex, localised interactions of several environmental drivers and the different response of organisms and populations. Megafauna diversity increased on steep slopes and topographic highs and decreased towards the thalweg. However, there is little evidence of a canyon endemic megafauna. Most species observed in the canyon also occur on the neighbouring continental slope, although comparative studies are needed to conclusively test this.

5) Elevated current velocities keep food for filter feeders in suspension and also expose hard substrata to which organisms can attach. Constriction of across-canyon tidal currents by the steep canyon walls and compensating amplification of alongcanyon velocities is one mechanism by which elevated and spatially variable current regimes may occur. A second is enhancement of near-bottom currents associated with the focusing of internal tides in the canyon. The complex bathymetry of Whittard Canyon (with sub-, super- and near-critical reflection regimes) and the likely presence of short but energetic nonlinear waveforms means that the internal tide field needs to be observed and modelled at high resolution in order to map current variability at the same scale as biological observations. Further complications arise from temporal changes to the internal tide field in response to the spring-neap cycle and on longer timescales in response to mesoscale activity and seasonal changes in stratification. 
6) The continuous sediment resuspension due to fishing, specifically bottom trawling in the Whittard Canyon can gradually reshape seafloor community structure and biodiversity (i.e. enhancing SPM fluxes, which smothers filter feeders and provides nutritional unsuitable material) reducing its original complexity.

Overall, this review has shown that perhaps the definition of an 'active' submarine canyon should not just be linked to the frequency of large-volume sediment flows and to unidirectional sediment transport from shallow waters to the deep-sea. A wide range of more frequent physical processes is 'active' in Whittard Canyon, both in terms of oceanography and sediment dynamics. Those equally contribute to the canyon formation and maintenance, and have a direct influence on the ecosystem functioning. It can be argued that those (tidal, seasonal) processes may be as important as, if not even more important than, large episodic events in shaping communities in submarine canyons. The spatial and temporal scales at which they occur are closer to the intrinsic scales of the biological patterns and ecological functioning within canyons, even if the latter ones are not well known yet. It is precisely a better insight in these intrinsic scales of biological patterns that is now urgently needed in order to fully understand the interaction between physical processes and biological observations, between environmental drivers and community distributions. Some of the complex patterns observed in Whittard Canyon are difficult to interpret based on existing observations. Further coordinated studies are therefore necessary to clarify the processes responsible for these highly variable faunal distributions. Sampling along bathymetric transects within branches of the Whittard Canyon and across the adjacent open slopes is limited, inconsistent between disciplines and faunal groups, and often confined to a single time point. Further advances will require concerted interdisciplinary research based on samples and observations made at the same locations, as well as better temporal coverage based on long-term observation and time-series programs. Ultimately, other submarine canyon systems, potentially with different 'activity' regimes, need to be investigated through similar large, multi-scale, multidisciplinary and well-coordinated studies to allow global insights in canyon processes to be reached. Although seemingly homogenous, nearby canyons may differ tremendously.

A good understanding of the fundamental active processes governing submarine canyons, including their spatial and temporal scale, is also of major importance in 
order to correctly evaluate the impact of human activities. Although most active canyons may exhibit broad ecosystem patterns similar to those observed in the Whittard Canyon, the shelf-to-canyon sediment delivery mechanisms are often different. The Whittard Canyon head is located $\sim 300 \mathrm{~km}$ from land, which means terrestrial sediment input is reduced compared to, for example, the Nazaré or Kaikoura Canyon. The effects of nepheloid layers and sediment flows caused by bottom trawling on canyon flanks may be very different in submarine canyons like Whittard Canyon, that are driven by tidal resuspension and limited downslope sediment flows, compared to systems with regular flows such as river-fed canyons. Equally, more indirect human impacts such as changes in water column temperature and density structure, caused by global warming, may have different impacts on the generation and propagation of internal tides, and hence on the crucial canyon 'activity' driving biodiversity and ecosystem functioning. Also acidification, reduced oxygen levels and the introduction of chemical pollutants are expected to have major effects on submarine canyon systems, and may cause reductions in faunal biomass and diversity. Major decreases in biomass will cause a widespread change in benthic ecosystems and the functions and services they provide, causing unprecedented challenges for the sustainable management of canyon systems. The more insights can be obtained into the activity and functioning of submarine canyons by means of integrated studies, the better such challenges can be answered in the future.

\section{ACKNOWLEDGEMENTS}

This study was partially supported by Marie Curie Actions through the project CEFMED (project number 327488) and HERMES (contract number GOCE-CT 2005511234-1). VAIH and KR are supported by the ERC Starting Grant project CODEMAP (Grant no 258482) and the NERC NC MAREMAP programme. AMW is funded by a Hardiman Research Scholarship, NUI Galway. RD and CG acknowledge the support of the programme RITMARE. JI was partially supported by a Marie Curie Intra-European Fellowship (MESMEC, Grant Agreement FP7-PEOPLE-2011-IEF no. 00879)

\section{REFERENCES}


Allen, S. and Durrieu de Madron, X. (2009). A review of the role of submarine canyons in deep-ocean exchange with the shelf. Ocean Science, 5, 607-620.

Amaro, T., Bianchelli, S., Billett, D. S. M., Cunha, M. R., Pusceddu, A, and Danovaro, R. (2010). The trophic biology of the holothurian Molpadia musculus: implications for organic matter cycling and ecosystem functioning in a deep submarine canyon. Biogeosciences, 7: 1-14.

Amaro, T., de Stigter, H., Lavaleye, M. \& Duineveld, G. (2015). Organic matter enrichment in the Whittard Channel (northern Bay of Biscay margin, NE Atlantic); its origin and possible effects on benthic megafauna. Deep-Sea Research Part I. 102, 90100 .

Amin, M. and Huthnance, J.M. (1999). The pattern of cross-slope depositional fluxes. Deep Sea Research Part I: Oceanographic Research Papers, 46, 1565-1591.

Baines, P. G. (1982). On internal tide generation models. Deep Sea Research Part A. Oceanographic Research Papers, 29,307-338.

Bianchelli S, Gambi C, Zeppilli D, Danovaro, R. (2010) Metazoan meiofauna in deep-sea canyons and adjacent open slopes: a large-scale comparison with focus on the rare taxa. Deep-Sea Research I, 57: 420-433

Billett, D.S.M., Bett, B.J., Reid, W.D.K., Boorman, B., Priede, M. (2010). Long-term change in the abyssal NE Atlantic: The 'Amperima Event' revisited, Deep-Sea Research II 57, 1406-1417.

Bourillet, J.F., Reynaud, J.Y., Baltzer, A., Zaragosi, S. (2003). The 'Fleuve Manche': the submarine sedimentary features from the outer shelf to the deep-sea fans. Journal of Quaternary Science 18, 261-282.

Bourillet, J.F., Zaragosi, S., Mulder, T. (2006). The French Atlantic margin and deepsea submarine systems. Geo-Marine Letters 26, 311-315.

Bosley, K. L., Lavelle, J. W., Brodeur, R. D., Wakefield, W. W., Emmett, R. L., Baker, E. T., \& Rehmke, K. M. (2004). Biological and physical processes in and around Astoria submarine Canyon, Oregon, USA. Journal of Marine Systems, 50(1), 21-37.

Bower, A. S., Lecann, B., Rossby, T., Zenk, W., Gould, J, Speer, K, Richardson, P.L., Prater, M.D. and Zhang, H.-M (2002). Directly measured mid-depth circulation in the northeastern North Atlantic Ocean. Nature, 419, 603-607.

Brooke, S. and Ross, S.W. (2014). First observations of the cold-water coral Lophelia pertusa in mid Atlanctic canyons of the USA. Deep-sea research II, 104, 245-251.

Cooper L.H.N. and Vaux D. (1949). Cascading over the continental slope of water from the Celtic Sea. Journal of the Marine Biology Association of the United Kingdom, 28, 719-750. 
Cunningham, M.J., Hodgson, S., Masson, D.G., Parson, L.M. (2005). An evaluation of along- and down-slope sediment transport processes between Goban Spur and Brenot Spur on the Celtic Margin of the Bay of Biscay. Sedimentary Geology 179, 99-116.

Danovaro R, Bianchelli S, Gambi C, Mea M, Zeppilli, D. (2009) $\alpha-, \beta-, \gamma-, \delta$ and $\varepsilon-$ diversity of deep-sea nematodes in canyons and open slopes of E-Atlantic and Mediterranean margins. Marine Ecology Progress Serie, 396: 197-209.

Danovaro R, Gambi C, Lampadariou N, Tselepides, A. (2008) Deep-sea biodiversity in the Mediterranean Basin: testing for longitudinal, bathymetric and energetic gradients. Ecography 31: 231-244.

Davies, J. S.,. Howell, K. L ; Stewart, H. A. , Guinan, J. and Golding, N. (2014). Defining biological assemblages (biotopes) of conservation interest in the submarine canyons of the South West Approaches (offshore United Kingdom) for use in marine habitat mapping. Deep Sea Research II, 104, 208-229.

Davies, J.S., Stewart, H.A., Narayanaswamy, B.E., Jacobs, C., Spicer, J., Golding, N., Howell, K.L. (2015). Benthic assemblages of the Anton Dohrn Seamount (NE Atlantic): defining deep-sea biotopes to support habitat mapping and management efforts with a focus on Vulnerable Marine Ecosystems. PLos ONE. . DOI: 10.1371/journal.pone.0124815.

de Graciansky, P.C., Poag, C.W. and Foss, G. (1985). Drilling on the Goban Spur: objectives, regional geological setting, and operational summary, in: de Graciansky, P.C., Poag, C.W., Cunningham, R., Loubere, P., Masson, D.G., Mazzullo, J.M., Montadert, L., Müller, C., Otsuka, K., Reynolds, L.A., Sigal, J., Snyder, S.W., Vaos, S.P., Waples, D. (Eds.), Initial Reports of the Deep Sea Drilling Project. U.S. Government Printing Office, Washington, pp. 5-13.

De Mol, L., Van Rooij, D., Pirlet, H., Greinert, J., Frank, N., Quemmerais, F. and Henriet, J.-P. (2011). Cold-water coral habitats in the Penmarc'h and Guilvinec Canyons (Bay of Biscay): Deep-water versus shallow-water settings. Marine Geology, 282 (1-2), 40-52.

Derégnaucourt, D. and Boillot, G. (1982). Structure géologique du golfe de Gascogne. Bull. BRGM 2, 149-178.

de Stigter, H.C., Boer, W., de Jesus Mendes, P.A., Jesus, C.C., Thomsen, L., van den Bergh, G.D., van Weering, T.C.E. (2007). Recent sediment transport and deposition in the Nazaré Canyon, Portuguese continental margin. Marine Geology 246, 144-164.

de Stigter, H., Lavaleye, M., Duineveld, G. and van Weering, T. (2008a). Sediment dynamics of the Whittard Canyon, Celtic Margin. Presentation at the 3rd HERMES workshop, Carvoeiro, Portugal, March 2008.

de Stigter, H.C. and shipboard scientific party (2008b). Report of cruise 64PE269 with RV Pelagia, Portimão - Cork, 19 May - 11 June 2007. Dispersal of 
anthropogenic lead in submarine canyons. NIOZ - Royal Netherlands Institute for Sea Research, Texel, The Netherlands, 65 pp.

Dingle, R.V., Scrutton, R.A. (1979). Sedimentary succession and tectonic history of a marginal plateau (Goban Spur, Southwest of Ireland). Marine Geology 33, 45-69.

Duineveld G., Lavaleye M.S.S., Berghuis E.M., de Wilde P. (2001). Activity and composition of the benthic fauna in the Whittard Canyon and the adjacent continental slope (NE Atlantic). Oceanologica Acta, 24, 69-83.

Dullo, W.-C., S. Flögel, and A. Rüggeberg (2008). Cold-water coral growth in relation to the hydrography of the Celtic and Nordic European continental margin. Marine Ecology Progress Series:165-176.

Duros, P., Fontanier, C., Metzger, E., Pusceddu, A., Cesbron, F., De Stigter, H.C., Bianchelli, S., Danovaro, R., Jorissen, F.J. (2011). Live (stained) benthic foraminifera in the Whittard Canyon, Celtic margin (NE Atlantic). Deep-Sea Research Part I: Oceanographic Research Papers 58, 128-146.

Duros, P., Fontanier, C., de Stigter, H.C., Cesbron, F., Metzger, E., Jorissen, F.J. (2012). Live and dead benthic foraminiferal faunas from Whittard Canyon (NE Atlantic): focus on taphonomic processes and paleo-environmental applications. Marine Micropaleontology 94-95: 25-44.

Egbert, G. D. (1997). Tidal data inversion: interpolation and inference. Progress in Oceanography, 40, 53-80. Tidal Science In Honour of David E.Cartwright.

Egbert, G. D. and Erofeeva, S. Y. (2002). Efficient inverse modeling of barotropic ocean tides. Journal of Atmospheric and Oceanic Technology, 19,183-204.

Evans, C.D.R. (1990). The geology of the western English Channel and its western approaches. HMSO for the British Geological Survey, London.

Evans, C.D.R., Hughes, M.J. (1984). The Neogene succession of the South Western Approaches, Great Britain. Journal of the Geological Society of London 141, 315326.

Flögel, S., Dullo, W. C., Pfannkuche, O. Kiriakoulakis, K. and Rüggeberg, A. (2014). Geochemical and physical constraints for the occurrence of living cold-water corals. Deep Sea Research Part II: Topical Studies in Oceanography 99:19-26.

Gambi, C., Vanreusel, A., Danovaro, R. (2003). Biodiversity of nematode assemblages from deep-sea sediments of the Atacama Slope and Trench (Southern Pacific Ocean). Deep-Sea Research I, 50, 103-117.

Gambi C, Pusceddu A, Benedetti-Cecchi L, and Danovaro R (2014). Species richness, species turnover, and functional diversity in nematodes of the deep Mediterranean Sea: searching for drivers at different spatial scales. Global ecology and biogeography, 23, 24-39 
Gambi C., Danovaro R. (2016). Biodiversity and life strategies of deep-sea meiofauna and nematode assemblages in the Whittard canyon (Celtic margin, NE Atlantic Ocean). Deep Sea Research Part I 108, 13-22.

Garrett, C. and Kunze, E. (2007). Internal tide generation in the deep ocean. Annual Review. Fluid Mech., 39, 57-87.

Gooday, A.J. (1988). A response by benthic foraminifera to phytodetritus deposition in the deep sea. Nature, 332: 70-73.

Gordon, R. L. and Marshall, N. F. (1976). Submarine canyons - internal wave traps. Geophysical Research Letters, 3, 622-624.

Gunton, L.M., Gooday, A.J., Glover, A.J., Bett, B.J. (2015a) Macrofaunal abundance and community composition at lower bathyal depths in different branches of the Whittard Canyon and on the adjacent slope (3500m; NE Atlantic). Deep Sea Research Part I 97, 29-39

Gunton, L.M., Neal, L., Gooday, A.J., Bett, B.J., Glover, A.G. (2015b). Local and regional variation in deep-sea polychaete diversity: canyon influence (Whittard Canyon system, NE Atlantic). Deep Sea Research Part I 106, 42-54. .

Hall, R. A. and Carter, G. S. (2011). Internal Tides in Monterey Submarine Canyon. Journal of Physical Oceanography, 41, 186-204.

Hall, R. A., Alford, M. H., Carter, G. S., Gregg, M. C., Lien, R.-C., Wain, D. J., and Zhao, Z. (2014). Transition from partly standing to progressive internal tides in Monterey Submarine Canyon. Deep-Sea Research II 104, 164-173.

Harris, P.T., Whiteway, T., (2011). Global distribution of large submarine canyons: geomorphic differences between active and passive continental margins. Marine Geology 285, 69-86.

Haughton, P. (2009) Hybrid sediment gravity flow deposits - Classification, origin and significance. Marine and Petroleum Geology, 26, 1900-1918.

Hedges J.I., Keil R.G., 1995. Sedimentary organic matter preservation: an assessment and speculative synthesis. Marine Chemistry, 49, 81-115.

Hickey, B. M. (1995). Coastal submarine canyons. Topographic effects in the ocean. SOEST Special publications, 95-110.

Holligan, P. M., Pingree, R. D., \& Mardell, G. T. (1985). Oceanic solitons, nutrient pulses and phytoplankton growth. Nature, 314, 348-350.

Holt, J. and Thorpe, S. (1997). The propagation of high frequency internal waves in the celtic sea. Deep Sea Research Part I: Oceanographic Research Papers, 4, 20872116. 
Hopkins, J. E., Stephenson, G. R., Green, J., Inall, M. E., and Palmer, M. R. (2014). Storms modify baroclinic energy uxes in a seasonally stratified shelf sea: Inertial-tidal interaction. Journal of Geophysical Research: Oceans, 119, 6863-6883.

Hotchkiss, F. S. and Wunsch, C. (1982). Internal waves in hudson canyon with possible geological implications. Deep-Sea Research Part a-Oceanographic Research Papers, 29,415-442.

Howell, K. L. (2010). A benthic classification system to aid in the implementation of marine protected area networks in the deep/high seas of the NE Atlantic. Biological Conservation 143:1041-1056.

Hunter, W.R., Jamieson, A.J., Huvenne, V., Witte, U. (2013). Sediment community responses to marine vs. terrigenous organic matter in a submarine canyon. Biogeosciences 10, 67-80.

Huvenne, V.A.I., Tyler, P.A., Masson, D.G., Fisher, E.H., Hauton, C., Hühnerbach, V., Le Bas, T.P., Wolff, G.A. (2011). A Picture on the Wall: Innovative Mapping Reveals Cold-Water Coral Refuge in Submarine Canyon. (J.M. Roberts, Ed.). Plos One 6, e28755.

Huvenne, Veerle A.I.; Davies, Jaime S. (2014). Towards a new and integrated approach to submarine canyon research. Introduction. Deep Sea Research Part II: Topical Studies in Oceanography, 104. 1-5

Inall, M., Aleynik, D., Boyd, T., Palmer, M., and Sharples, J. (2011). Internal tide coherence and decay over a wide shelf sea. Geophysical Research Letters, 38, L23607, doi:10.1029/2011GL049943.

Ingels, J., Kiriakoulakis, K., Wolff, G.A., Vanreusel, A. (2009). Nematode diversity and its relation to the quantity and quality of sedimentary organic matter in the deep Nazare Canyon, Western Iberian Margin. Deep-Sea Research Part I-Oceanographic Research Papers 56(9), 1521-1539.

Ingels J., Tchesunov A.V., Vanreusel A. (2011a) Meiofauna in the Gollum Channels and the Whittard Canyon, Celtic Margin - How Local Environmental Conditions Shape Nematode Structure and Function. Plos One 6 (5), 1-15.

Ingels, J., Billett, D., Van Gaever, S., Vanreusel, A. (2011b) An insight into the feeding ecology of deep-sea canyon nematodes - Results from field observations and the first in-situ C-13 feeding experiment in the Nazare Canyon. Journal of Experimental Marine Biology and Ecology 396(2), 185-193.

Ingels, J., Billett, D.S.M., Kiriakoulakis, K., Wolff, G.A., Vanreusel, A. (2011c). Structural and functional diversity of Nematoda in relation with environmental variables in the Setúbal and Cascais canyons, Western Iberian Margin. Deep Sea Research Part II: Topical Studies in Oceanography 58(23-24), 2354-2368.

Ingels, J., Vanreusel, A., Romano, C., Coenjaerts, J., Mar Flexas, M., Zúñiga, D., Martin, D., 2013a. Spatial and temporal infaunal dynamics of the Blanes submarine 
canyon-slope system (NW Mediterranean); changes in nematode standing stocks, feeding types and gender-life stage ratios. Progress in Oceanography 118, 159-174.

Ingels, J., Vanreusel, A., 2013b. The importance of different spatial scales in determining structural and functional characteristics of deep-sea infauna communities. Biogeosciences 10(7), 4547-4563.

Ismail, K., Robert, K. and Huvenne V. (submitted). Quantifying marine landscape heterogeneity in submarine canyons.

Ivanov V.V., Shapiro G.I., Huthnance J.M., Aleynik D.L., Golovin P.N. (2004). Cascades of dense water around the world ocean. Progress in Oceanography, 60, 4798.

Joint, I.R., Owens, N.J.P. and Pomroy, A.J. (1986). Seasonal production of photosynthetic picoplankton and nanoplankton in the Celtic Sea. Marine Ecology Progress Series, 28, 251-258.

Joint I, Wollast R, Chou L, Batten S, Elskens M, et al. (2001) Pelagic production at the Celtic Sea shelf break. Deep-Sea Research Part II: Topical Studies in Oceanography 48: 3049-3081

Jamieson, A.J., Kilgallen, N.M., Rowden, A.A., Fujii, T., Horton, T., Lorz, A.-N., Kitazawa, K. and Priede, I.G. (2011). Bait-attending fauna of the Kermadec Trench, SW Pacific Ocean: evidence for an ecotone across the abyssal-hadal transition zone. Deep-Sea Research Part I 58, 49-62.

Johnson, M. P.; White, M.; Wilson, A.; Würzberg, L.; Schwabe, E.; Folch, H. and Allcock, A. L. (2013). A vertical wall dominated by Acesta excavata and Neopycnodonte zibrowii, part of an undersampled group of deep-sea habitats. PLoS ONE 8:e79917.

Kershaw, C., Whitfield, E., Wilson, A., White, M., Kirby, J, and Kiriakoulakis, K. (2015) Sedimentation and organic biogeochemistry in the Whittard Canyon, NE Atlantic. Inaugural Meeting of the Deep-Sea Ecosystems Special Interest Group, Challenger Society for Marine Science, Liverpool, July 2015.

Kiriakoulakis K., Blackbird S., Ingels J., Vanreusel A., Wolff G.A. (2011). Organic geochemistry of submarine canyons: The Portuguese margin, Deep Sea Research Part II, 58, 2477-2488.

Lambeck, K., (1996). Glaciation and sea-level change for Ireland and the Irish Sea since Late Devensian/Midlandian time. Journal of the Geological Society of London $153,853-872$.

Lavaleye M., Duineveld G., Lundälv T., White M., Guihen D., Kiriakoulakis K., Wolff G.A. (2009). Cold-Water Corals on the Tisler Reef. Preliminary observations on the dynamic reef environment. Oceanography, 22, 76-84. 
Lavaleye, M. and shipboard scientific crew. (2009). CORALFISH-HERMIONE Cruise Report, Cruise 64PE313, Galway-Lisbon, 16 Oct - 5 Nov 2009, Belgica Mound Province (CoralFISH \& HERMIONE), Whittard Canyon (HERMIONE) and Galicia Bank area (BIOFUN). NIOZ - Royal Netherlands Institute for Sea Research, Texel, The Netherlands, 46 pp.

Leduc, D., Rowden, A.A., Probert, P.K., Pilditch, C.A., Nodder, S.D., Vanreusel, A., Duineveld, G.C.A., Witbaard, R. (2012). Further evidence for the effect of particlesize diversity on deep-sea benthic biodiversity. Deep Sea Research Part I: Oceanographic Research Papers, 63, 164-169.

Leduc, D., Rowden, A., Nodder, S., Berkenbusch, K., Probert, P., Hadfield, M. (2014). Unusually high food availability in Kaikoura Canyon linked to distinct deepsea nematode community. Deep Sea Research Part II: Topical Studies in Oceanography 104, 310-318.

Lins, L., Vanreusel, A., van Campenhout, J., Ingels, J. (2013). Selective settlement of deep-sea canyon nematodes after resuspension - an experimental approach. Journal of Experimental Marine Biology and Ecolology, 441, 110-116.

Martín, J., Puig, P., Palanques, A., Masqué, P., García-Orellana, J. (2008). Effect of commercial trawling on the deep sedimentation in a Mediterranean submarine canyon. Marine Geology 252, 150-155.

Martín, J., Palanques, A., Vitorino, J., Oliveira, A., de Stigter, H.C. (2011). Nearbottom particulate matter dynamics in the Nazare submarine canyon under calm and stormy conditions. Deep-Sea Research Part II, Topical Studies in Oceanography 58, 2388-2400.

Martín, J., Puig, P., Palanques, A., and Ribó, M. (2014). Trawling-induced daily sediment resuspension in the flank of a Mediterranean submarine canyon. Deep Sea Research Part II: Topical Studies in Oceanography, 104, 174-183.

Masson D.G., Huvenne V.A.I., de Stigter H., Wolff G.A., Kiriakoulakis K., Arzola R.G., Blackbird S. (2010). Efficient burial of carbon in a submarine canyon. Geology, 38, 831-834.

McCave, I.N. (1986). Local and global aspects of the bottom nepheloid layers in the world ocean. Netherlands Journal of Sea Research 20, 167-181.

Meyers, P. A. (1997) Organic geochemical proxies of paleoceanographic, paleolimnologic and paleoclimatic processes. Organic Geochemistry, 27, 213-250

Morris K.J., Tyler R.A., Masson D.G. Huvenne V.I.A. and Rogers A. (2013). Distribution of cold water corals in the Whittard Canyon NE Atlantic. Deep Sea Research II, 92, 136-144.

Muller-Navarra D.C., Brett M.T., Liston A.M. and Goldman C.R. (2000). A highly unsaturated fatty acid predicts carbon transfer between primary producers and consumers. Nature, 403, 74-77. 
Mulder, T., Zaragosi, S., Garlan, T., Mavel, J., Cremer, M., Sottolichio, A., Sénéchal, N., Schmidt, S. (2012). Present deep-submarine canyons activity in the Bay of Biscay (NE Atlantic). Marine Geology, 295-298, 113-127.

Narayanaswamy, B. E., Hughes, D. J., Howell, K. L., Davies, J., and Jacobs, C. (2013). First observations of megafaunal communities inhabiting George Bligh Bank, Northeast Atlantic. Deep Sea Research Part II: Topical Studies in Oceanography.

Nash, J. D., Kunze, E., Toole, J. M., and Schmitt, R. W. (2004). Internal tide reflection and turbulent mixing on the continental slope. Journal of Physical Oceanography, 34,1117-1134.

Pérez, F. F., Ríos, A. F., King, B. A., Pollard, R. T. (1995). Decadal changes of the $\theta-$ S relationship of the Eastern North Atlantic Central Water. Deep Sea Research Part I: Oceanographic Research Papers, 42, 1849-1864.

Pham, C.K., Ramirez-Llodra, E.R., Alt, C., Amaro, T., et al. (2014) Marine litter distribution and density in European seas, from the shelves to deep basins. PLoS ONE 9(4):e95839.

Pingree, R. (1980). Physical oceanography of the celtic sea and english channel. Elsevier Oceanography Series, 24, 415-465.

Pingree, R. and Mardell, G. (1985). Solitary internal waves in the celtic sea. Progress in Oceanography, 14, 431-441.

Pingree R.D. and LeCann, B. (1989). Celtic and Armorican slope and shelf residual currents Progress in Oceanography, 23, 303-338.

Pingree, R. D., Sinha, B., Griffiths, C.R. (1999). Seasonality of the European slope current (Goban Spur) and ocean margin exchange. Continental Shelf Research 19, 929-975.

Pingree, R.D. and Le Cann, B. (1990). Structure, strength and seasonality of the slope currents in the Bay of Biscay region. Journal of the Marine Biological Association of the United Kingdom, 70, 857-885.

Pollard, R. T., Grifftths, M. J., Cunningham, S. A., Read, J. F., Pérez, F. F., Ríos, A. F. (1996). Vivaldi 1991-A study of the formation, circulation and ventilation of Eastern North Atlantic Central Water. Progress in Oceanography, 37,167-192.

Praeg, D., McCarron, S., Dove, D., Ó Cofaigh, C., Scott, G., Monteys, X., Facchin, L., Romeo, R., Coxon, P. (2015). Ice sheet extension to the Celtic Sea shelf edge at the Last Glacial Maximum. Quaternary Science Reviews, 111, 107-112.

Puig, P. and Palanques, A., (1998). Temporal variability and composition of settling particle fluxes on the Barcelona continental margin (Northwestern Mediterranean). Journal of Marine Research, 56, 639-654. 
Puig, P., Canals, M., Company, J.B., Martín, J., Amblas, D., Lastras, G., Palanques, A., Calafat, A.M. (2012). Ploughing the deep sea floor. Nature 489, 286-289.

Puig, P., Palanques, A., Martín, J. (2014). Contemporary Sediment-Transport Processes in Submarine Canyons. Annual Review of Marine Science, 6, 53-77.

Pusceddu A, Mea M, Canals M, Heussner S, Durrieu de Madron X, Sanchez-Vidal A, Bianchelli S, Corinaldesi C, Dell'Anno A, Thomsen L, Danovaro R (2013) Major consequences of an intense dense shelf water cascading event on deep-sea benthic trophic conditions and meiofaunal biodiversity. Biogeosciences 10(4): 2659-2670

Reid, G.S., Hamilton, D. (1990). A Reconnaissance Survey of the Whittard Sea Fan, Southwestern Approaches, British-Isles. Marine Geology 92, 69-86.

Rees, A.P., Joint, I. and Donald. K.M. (1999). Early spring bloom phytoplanktonnutrient dynamics at the Celtic Sea Shelf Edge. Deep Sea Research, 46, 483-510.

Rice, A. L., Tyler, P. A., \& Paterson, G. J. L. (1992). The pennatulid Kophobelemnon stelliferum (Cnidaria: Octocorallia) in the porcupine seabight (north-east Atlantic Ocean). Journal of the Marine Biological Association of the United Kingdom, 72(02), 417-434.

Roberts, J. M., L. A. Henry, D. Long, and J. P. Hartley (2008). Cold-water coral reef frameworks, megafaunal communities and evidence for coral carbonate mounds on the Hatton Bank, north east Atlantic. Facies, 54, 297-316.

Robert, K., D. O. B. Jones, P. A. Tyler, D. Van Rooij and V. A. I. Huvenne (2015). Finding the hotspots within a biodiversity hotspot: fine-scale biological predictions within a submarine canyon using high-resolution acoustic mapping techniques. Marine Ecology, 36(4), 1256-1276. DOI: 10.1111/maec.12228.

Romano, C., Coenjaerts, J., Mar Flexas, M., Zúñiga, D., Vanreusel, A., Company, J.B., Martin, D. (2013). Spatio-temporal variability of meiobenthic density in the Blanes submarine canyon (NW Mediterranean). Progress in Oceanography 118, 144158.

Ryan, J. P., Chavez, F. P., \& Bellingham, J. G. (2005). Physical-biological coupling in Monterey Bay, California: topographic influences on phytoplankton ecology. Marine Ecology Progress Series, 287, 23-32.

Sanchez-Vidal, A., Canals, M., Calafat, A.M., Lastras, G., Pedrosa-Pàmies, R., Menéndez, M., Medina, R., Company, J.B., Hereu, B., Romero, J., Alcoverro, T. (2012). Impacts on the Deep-Sea Ecosystem by a Severe Coastal Storm. PlosOne 71, e30395.

Scourse, J., Uehara, K., Wainwright, A. (2009). Celtic Sea linear tidal sand ridges, the Irish Sea Ice Stream and the Fleuve Manche : palaeotidal modelling of a transitional passive margin depositional system. Marine Geology, 259, 102-111. 
Sharples, J., Tweddle, J. F., Mattias Green, J., Palmer, M. R., Kim, Y.-N., Hickman, A. E., Holligan, P. M., Moore, C. M., Rippeth, T. P., Simpson, J. H., et al. (2007). Spring-neap modulation of internal tide mixing and vertical nitrate fluxes at a shelf edge in summer. Limnology and Oceanography, 52, 1735-1747.

Sibuet, J.-C., Monti, S., Loubrieu, B., Mazé, J.-P., Srivastava, S. (2004). Carte bathymétrique de l'Atlantique nord-est et du golfe de Gascogne. Bulletin du Société Géologique de France 175, 429-442.

Soetaert, K. and Heip, C. (1995) Nematode assemblages of deep-sea and shelf break sites in the North Atlantic and Mediterranean Sea. Marine Ecology Progress Series 125: $171-183$

Skliris, N. and Denidi, S. (2006). Plankton dynamics controlled by hydrodynamic processes near a submarine canyon off NW corsican coast: a numerical modelling study. Continental Shelf Research, 26, 1336-1358.

Stewart, H.A., Davies, J.S., Guinan, J.C., Howell, K.L. (2014). The Dangeard and Explorer Canyons, South-West Approaches, UK: Geology, sedimentology and newly discovered cold-water coral mini-mounds. Deep-Sea Research II 104, 230-244.

Tchesunov, A.V., Ingels, J., Popova, E.V. (2012). Marine free-living nematodes associated with symbiotic bacteria in deep-sea canyons of north-east Atlantic Ocean. Journal of the Marine Biological Association of the United Kingdom 92(6), 12571271.

Thorpe, S. A. (2005). The Turbulent Ocean. Cambridge University Press.

Toucanne, S., Zaragosi, S., Bourillet, J.F., Naughton, F., Cremer, M., Eynaud, F., Dennielou, B., (2008). Activity of the turbidite levees of the Celtic-Armorican margin (Bay of Biscay) during the last 30,000 years: Imprints of the last European deglaciation and Heinrich events. Marine Geology, 247, 84-103.

Turnewitsch R., Springer B. M., Kiriakoulakis K., Vilas J. C., Arístegui J., Wolff G. A., Peine F., Werk S., Graf G., Waniek. J. (2007). Approaching the true concentration of particulate organic carbon in seawater: the relative methodological importance of artificial organic carbon gains and losses in two-filtration-based techniques. Marine Chemistry, 105, 208-228.

Tyler, P. A., and H. Zibrowius (1992). Submersible observations of the invertebrate fauna on the continental-slope southwest of ireland (NE atlantic-ocean). Oceanologica Acta 15:211-226.

Tyler P., Amaro T., Azorla R., Cunha M., de Stigter H., Gooday A., Huveene V., Ingels J., Kiariakoulakis K., Lastras G., Masson D., Oliveira A., Pattenden A., Vanreusel A., van Weering T., Vitorino J., Witte U., Wolff G.A. (2009). Europe's 'Grand Canyon': the Nazaré Submarine Canyon. Oceanography, 22, 46-57. 
Vanhove, S., Vermeeren, H. and Vanreusel, A., (2004). Meiofauna towards the south Sandwich Trench (750-6300 m), focus on nematodes. Deep-Sea Research Part II, 51, 1665-1687.

Vanreusel, A., Fonseca, G., Danovaro, R., da Silva, M., Esteves, A., Ferrero, T., Gad, G., Galtsova, V., Gambi, C., Genevois, V., Ingels, J., Ingole, B., Lampadariou, N., Merckx, B., Miljutin, D., Miljutina, M., Muthumbi, A., Netto, S., Portnova, D., Radziejewska, T., Raes, M., Tchesunov, A., Vanaverbeke, J., Van Gaever, S., Venekey, V., Bezerra, T., Flint, H., Copley, J., Pape, E., Zeppilli, D., Martinez, P., Galeron, J. (2010). The contribution of deep-sea macrohabitat heterogeneity to global nematode diversity. Marine Ecology-an Evolutionary Perspective 31(1), 6-20.

van Aken, H. M. (2000a). The hydrography of the mid-latitude northeast Atlantic Ocean: I: The deep water masses. Deep Sea Research Part I: Oceanographic Research Papers 47:757-788.

van Aken, H. M. (2000b). The hydrography of the mid-latitude Northeast Atlantic Ocean: II: The intermediate water masses. Deep Sea Research Part I: Oceanographic Research Papers 47:789-824.

van Rooij, D., Iglesias, J., Hernández-Molina, F.J., Ercilla, G., Gomez-Ballesteros, M., Casas, D. Llave, E., De Hauwere, A., Garcia-Gil, S., Acosta, J. and Henriet, J.P. (2010a). The Le Danois Contourite Depositional System: interactions between the Mediterranean outflow water and the upper Cantabrian slope (North Iberian margin). Marine Geology, 274, 1-20.

van Rooij, D., de Mol, L., Ingels, J., Versteeg, W., Ruggeberg, A., Jauniaux, T., party, the shipboard scientific party (2010b) Cruise Report Belgica 10/17b, Belgica BiSCOSYSTEMS II, Leg 2, Whittard Canyon. Renard Centre of Marine Geology \& Marine Biology Research Group, Ghent University, Belgium, pp. 39.

van Weering, T.C.E., Thomsen, L., van Heerwaarden, J., Koster, B., Viergutz, T. (2000). A seabed lander and new techniques for long term in situ study of deep-sea near bed dynamics. Sea Technology 41, 17-27.

Vlasenko, V., Stashchuk, N., Inall, M. E., and Hopkins, J. E. (2014). Tidal energy conversion in a global hot spot: On the 3-d dynamics of baroclinic tides at the celtic sea shelf break. Journal of Geophysical Research: Oceans, 119(6):3249-3265.

Weston, J. (1985). Comparison between Recent benthic foraminiferal faunas of the Porcupine Seabight and Western Approaches continental slope. Journal of Micropaleontology. 4: 165-183.

White M., Mohn C., Kiriakoulakis K., 2015. Environmental Sampling. In: Biological sampling in the deep-sea: An (illustrated) manual of tools and techniques (eds: Clark M., Consalvey M., Rowden A.) Wiley-Blackwell.

Wilson, M.F.J., O'Connell, B., Brown, C., Guinan, J.C. \& Grehan, A.J. (2007). Multiscale Terrain Analysis of Multibeam Bathymetry Data for Habitat Mapping on the Continental Slope. Marine Geodesy, 30, 3-35. 
Wilson, A.M., Raine, R., Mohn,C. and White, M. (2015a). Nepheloid layer distribution in the Whittard Canyon, NE Atlantic Margin. Marine Geology, 367,130142.

Wilson, A.M., Raine, R., Gerritsen, H., Kiriakoulakis, K., Blackbird, B., Allcock, L. and White, M. (2015b) Anthropogenic influence on sediment transport in the Whittard Canyon, NE Atlantic. Marine Pollution Bulletin 101, 320-329..

Wollast, R. and Chou, L. (2001). The carbon cycle at the ocean margin in the northern Gulf of Biscay. Deep Sea Research Part II, 48, 3265-3293.

Xu, J.P., Noble, M.A., Eittreim, S.L., Rosenfeld, L.K., Schwing, F.B., Pilskaln, C.H., 2002. Distribution and transport of suspended particulate matter in Monterey Canyon, California. Marine Geology 181, 215-234.

Zaragosi, S., Bourillet, J.F., Eynaud, F., Toucanne, S., Denhard, B., Van Toer, A., Lanfumey, V., 2006. The impact of the last European deglaciation on the deep-sea turbidite systems of the Celtic-Armorican margin (Bay of Biscay). Geo-Marine Letters 26, 317-329. 
Legends to Figures

Figure 1. (a) Location map of the Whittard Canyon along the Celtic Margin, Bay of Biscay. Bathymetry data from GEBCO (2003). (b) multibeam bathymetric map of the Whittard Canyon and proximal part of the Whittard Channel and adjacent slopes, showing all the stations used for this paper, listed by author and data type (meio-, macro-, megafauna, biogeochemistry, sedimentology, watercolumn or current measurements). Bathymetry courtesy of the Geological Survey of Ireland (GSI Dublin) for the upper canyon, the HMS Scott for the lower canyon and Whittard Channel, and the MESH project for the Explorer \& Dangeard Canyons.

Figure 2. Sparker profile 2007/06/09 over Explorer interfluve, part of the eastern Whittard Canyon System, showing interpreted Neogene formations and the subtle sea-bed expression of the Explorer cold-water coral mini-mound province. Location of the profile is indicated in Fig. 1.

Figure 3. (a) Depth-integrated baroclinic $\mathrm{M}_{2}$ energy flux in the Whittard Canyon region. Vectors are plotted every 10 model grid points $(\approx 5 \mathrm{~km})$ in each direction. The underlying colour is the energy flux magnitude. (b) Location of intermediate nepheloid layers observed along four canyon branches (WC1-4), 2011-2014. Observations from repeats years are green, single observations are blue. (c) Nearbottom $\mathrm{M}_{2}$ tidal current ellipses from the same model as (a). Flux vectors and current ellipses shallower than $300 \mathrm{~m}$ are omitted for clarity. Depth contours are plotted every $300 \mathrm{~m}$.

Figure 4. Near-bed, along-canyon current velocity and cumulative water flux (upper panel) and suspended particulate matter (SPM) concentration and cumulative SPM flux (lower panel), recorded by the BOBO lander at $1479 \mathrm{~m}$ water depth in the western branch of the Whittard Canyon, between 30 October 2009 and 23 June 2010. Note sediment gravity flow event at the $14^{\text {th }}$ January 2010 . 
Figure 5. Lithogenic content (as \% of dry sediment) of surface sediments $(0-1 \mathrm{~cm})$ and sediment traps (mounted on benthic landers) from the Whittard Canyon branches (for location details see Fig. 1). Details of sampling stations given in Table 1. The samples were collected during several cruises from 2007 to 2013.

Figure 6. Total organic carbon (TOC) content (as \% of dry sediment) of surface sediments $(0-1 \mathrm{~cm})$ and sediment traps (mounted on benthic landers) from the Whittard Canyon branches (for location details see Fig. 1). Details of sampling stations given in Table 1. The samples were collected during several cruises from 2007 to 2013.

Figure 7. Mean molar (organic) Carbon to (total) Nitrogen ratio, of surface sediments $(0-1 \mathrm{~cm})$ and sediment traps (mounted on benthic landers) from the Whittard Canyon branches (for location details see Fig. 1). Details of sampling stations given in Table 1. The samples were collected during several cruises from 2007 to 2013.

Figure 8. Fluctuations in turbidity (measured as optical backscatter - in black) and chlorophyll (measured as fluorescence - in green) near the bottom of the Whittard Canyon (A) clearly correlate with fluctuations in near-bed current speed (B), indicating that bottom sediment and phytodetritus are resuspended by tidal currents in the canyon. Data recorded with an ALBEX bottom lander at $2064 \mathrm{~m}$ depth in the eastern middle branch of Whittard Canyon.

Figure 9. Meiofaunal abundance (a) and diversity as number of taxa (b) along a bathymetric transect in the middle branches of the Whittard Canyon. Data at 700 and $1000 \mathrm{~m}$ are published in Ingels et al. (2011) while data from 1483 to $2939 \mathrm{~m}$ are summarized from Gambi and Danovaro (submitted). 
Figure 10. Nematode diversity as expected genera number EG(51) (a) and trophic structure (b) along a bathymetric transect in the middle branches of the Whittard Canyon. Reported are: 1A (selective deposit feeders); 1B (non-selective deposit feeders); 2A (epigrowth feeders) and 2B (predators/omnivores). Data at 700 and 1000 $\mathrm{m}$ are published in Ingels et al. (2011) while data from 1483 to $2939 \mathrm{~m}$ are summarized from Gambi and Danovaro (submitted).

Figure 11. Macrofauna abundance in Whittard Canyon (ind $\mathrm{m}^{-2}$ ).

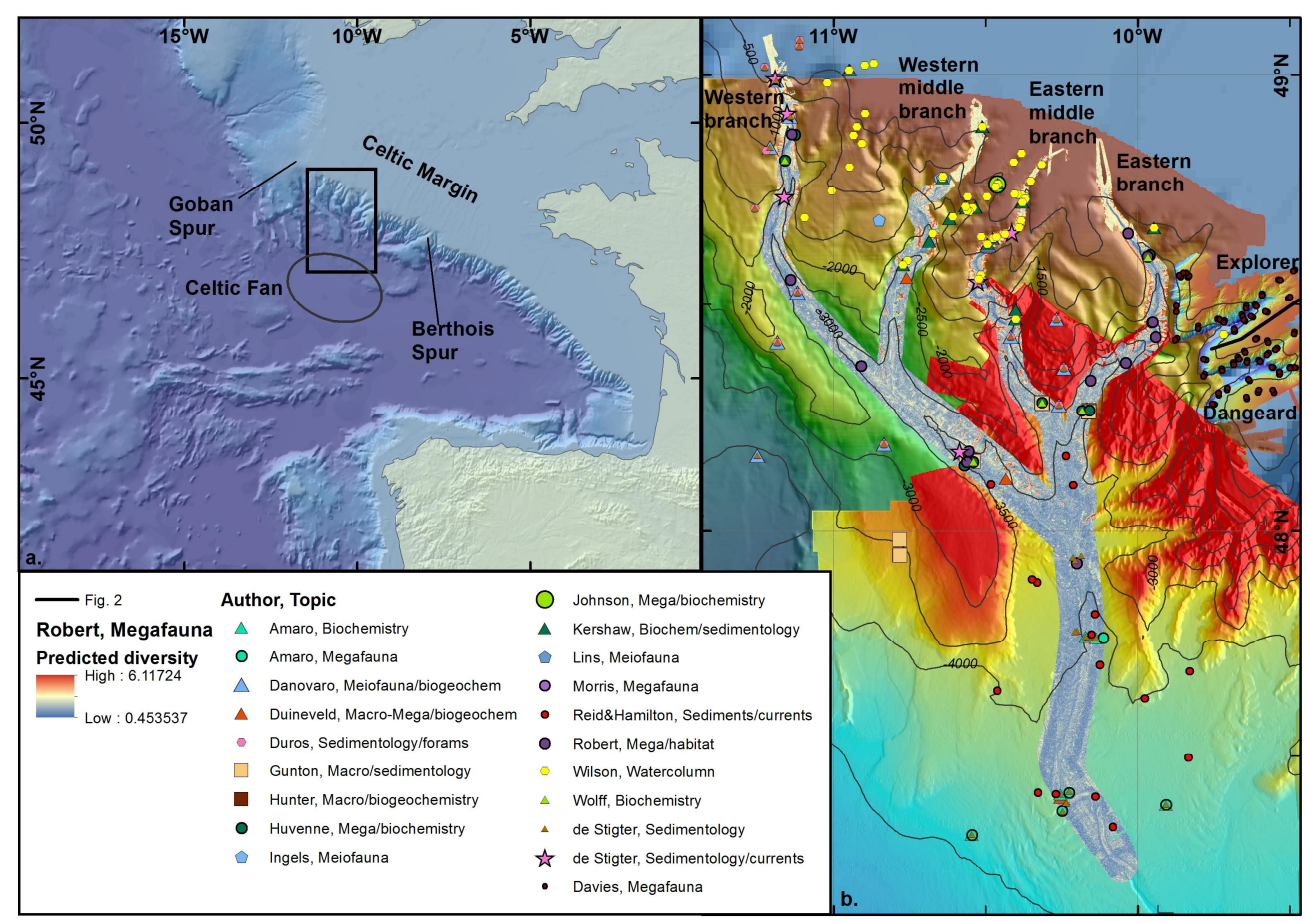

Figure 1 


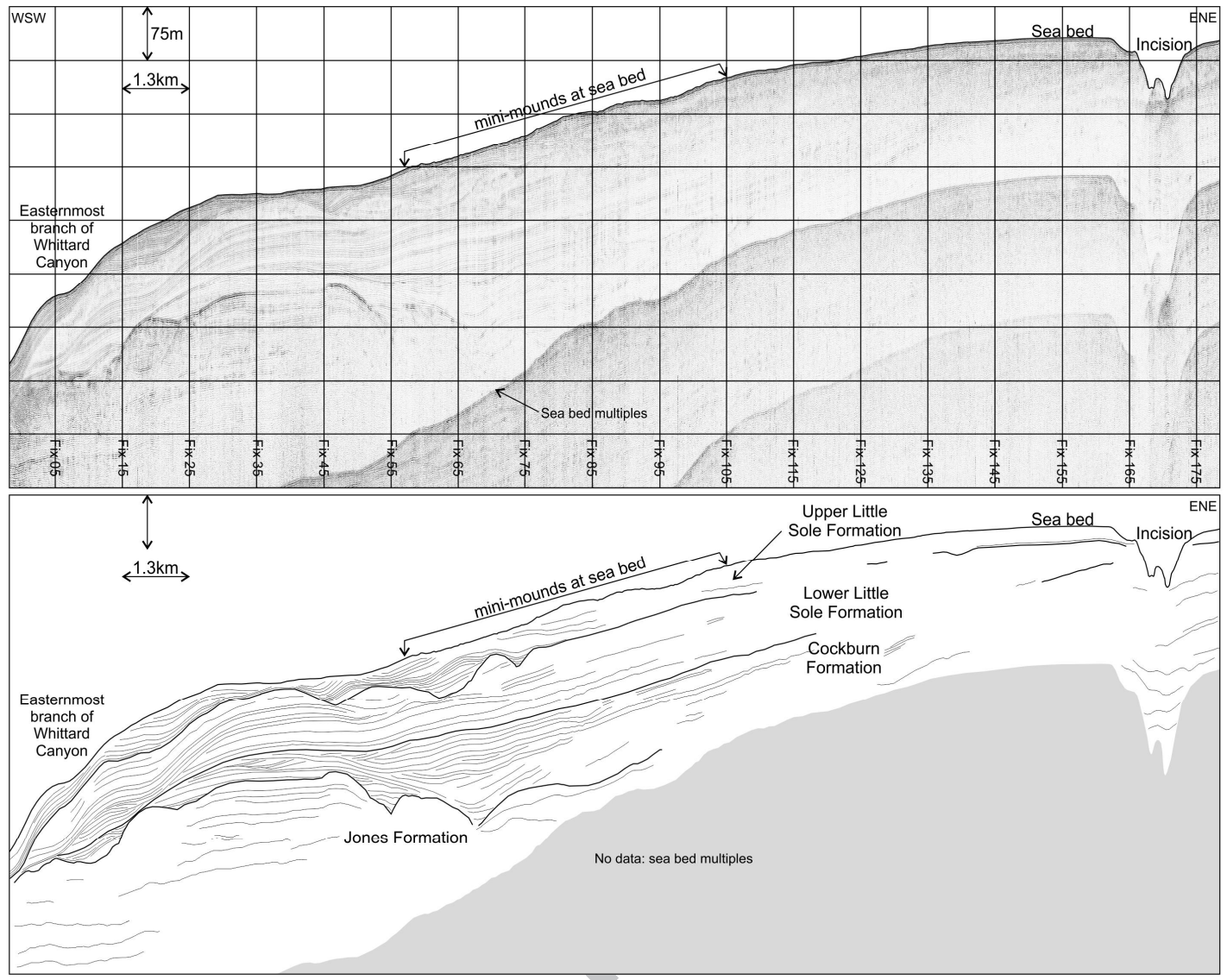

Figure 2 


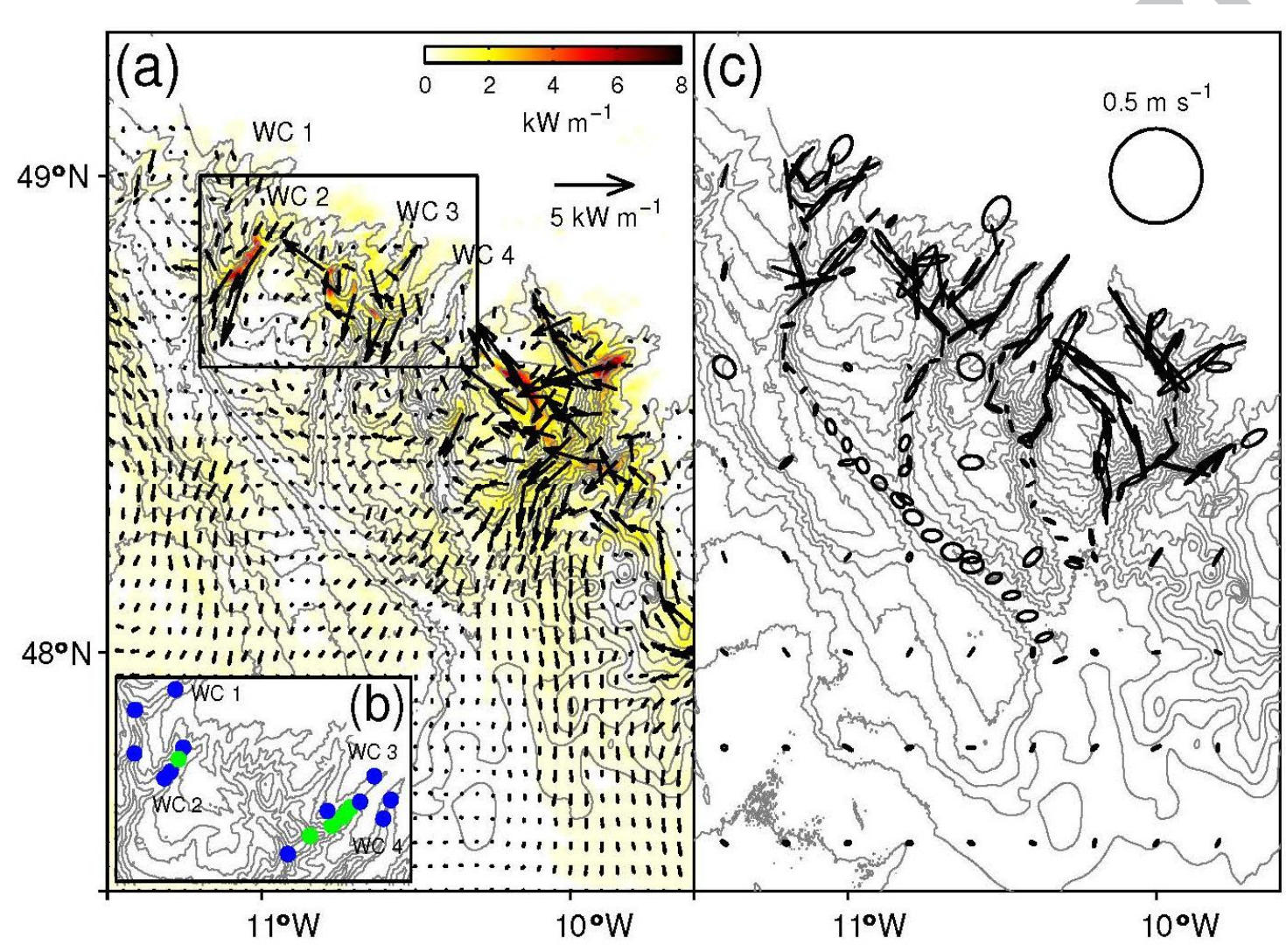

Figure 3 


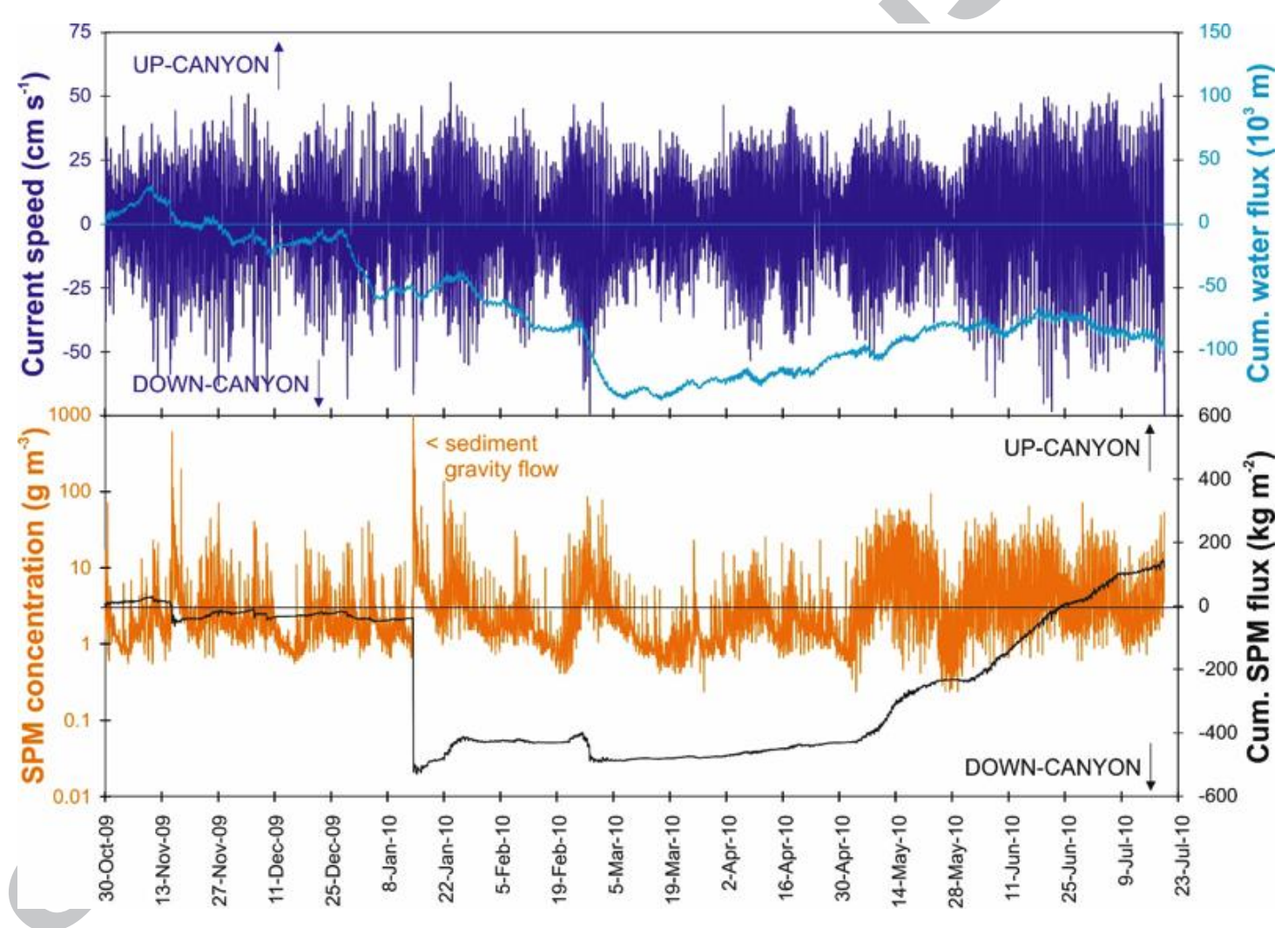

Figure 4 


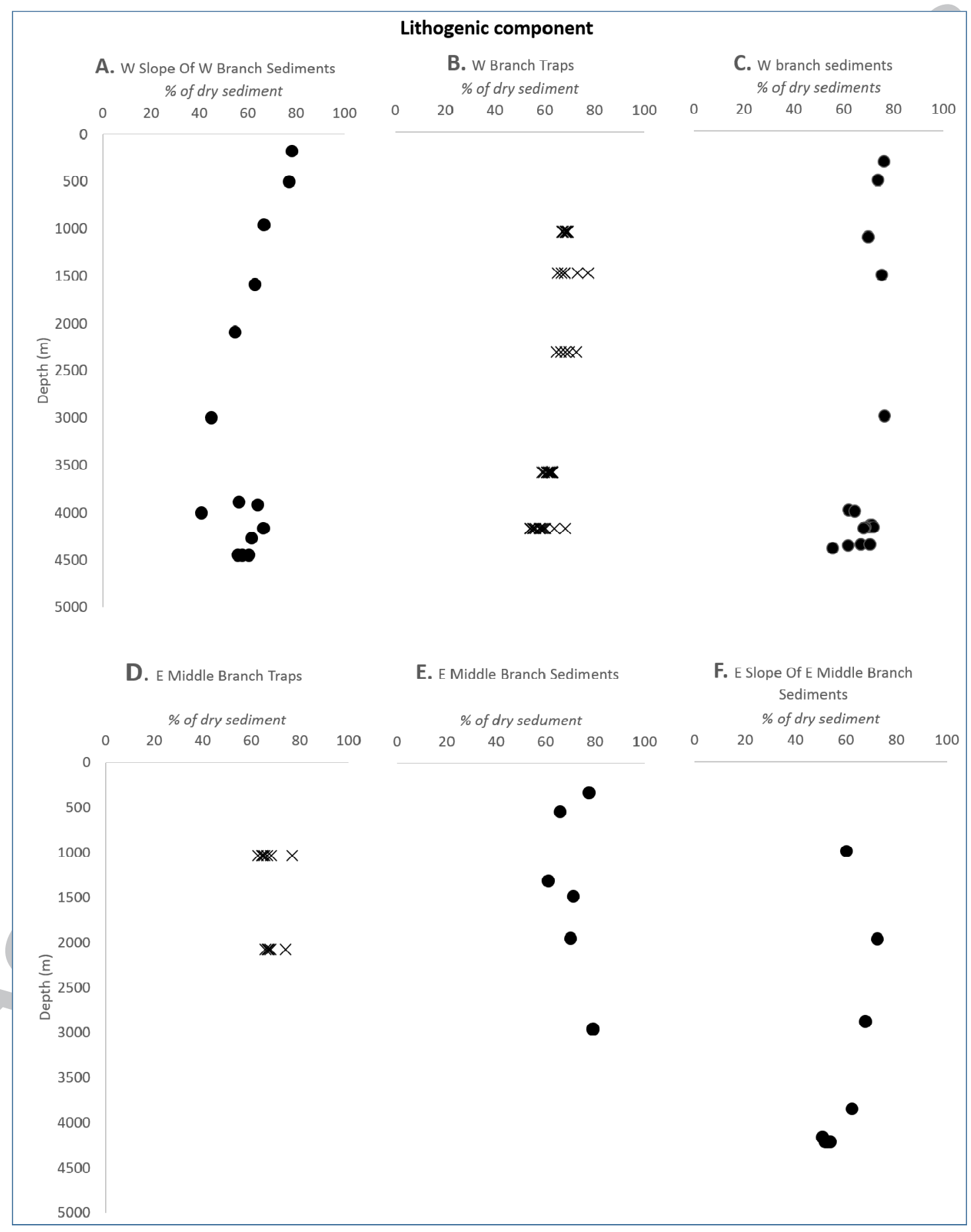

Figure 5 


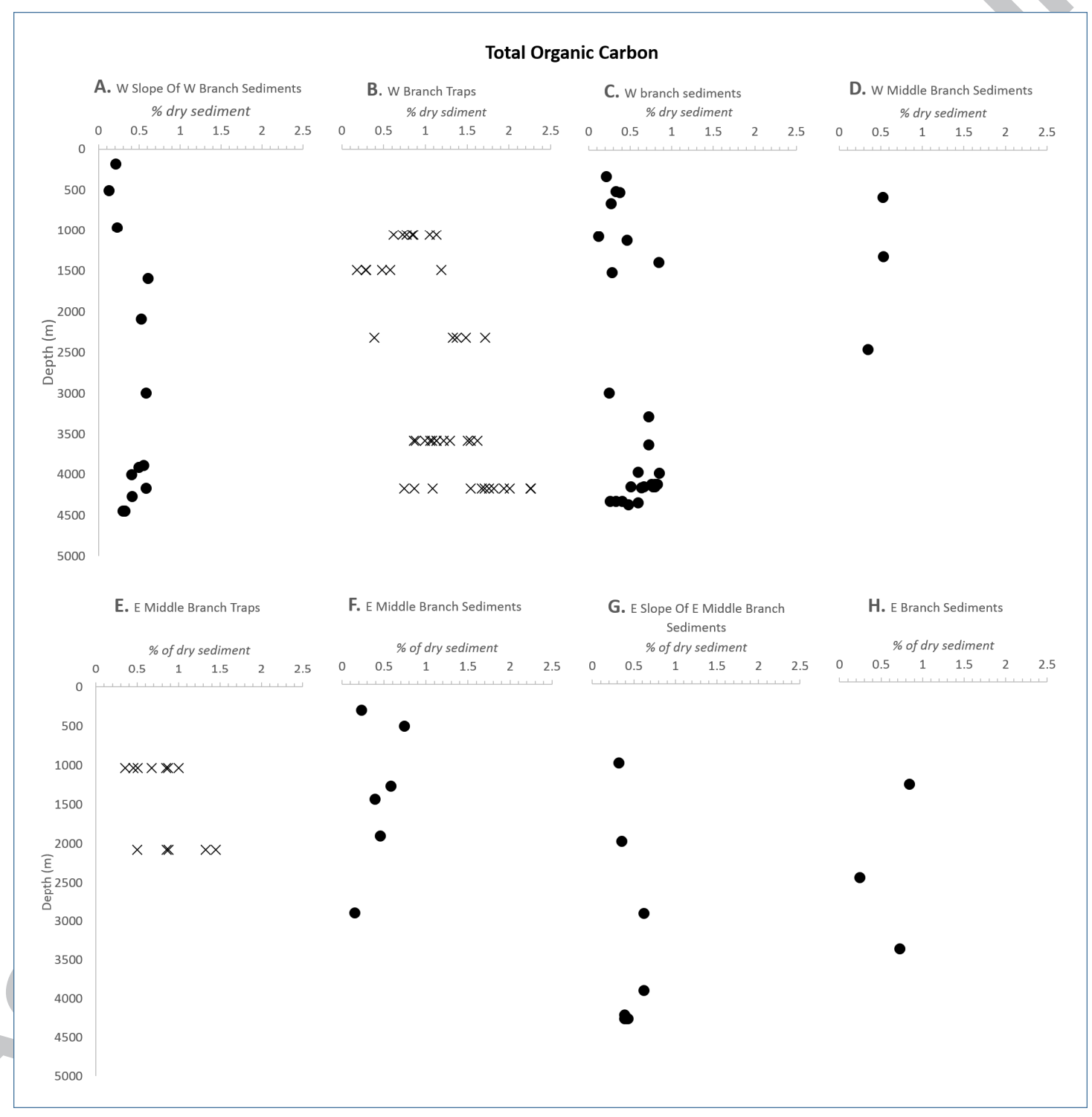

Figure 6 


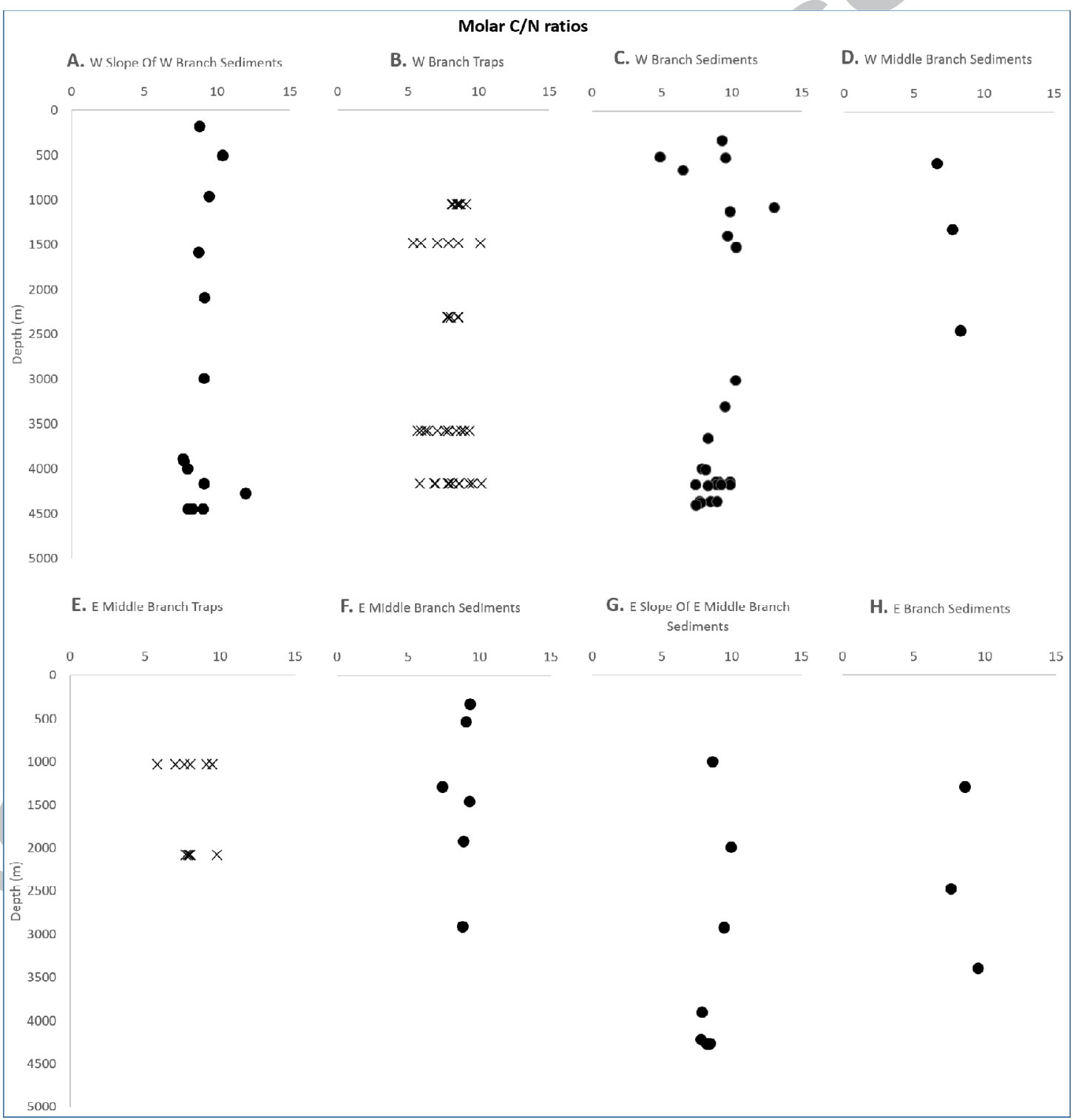

Figure 7 


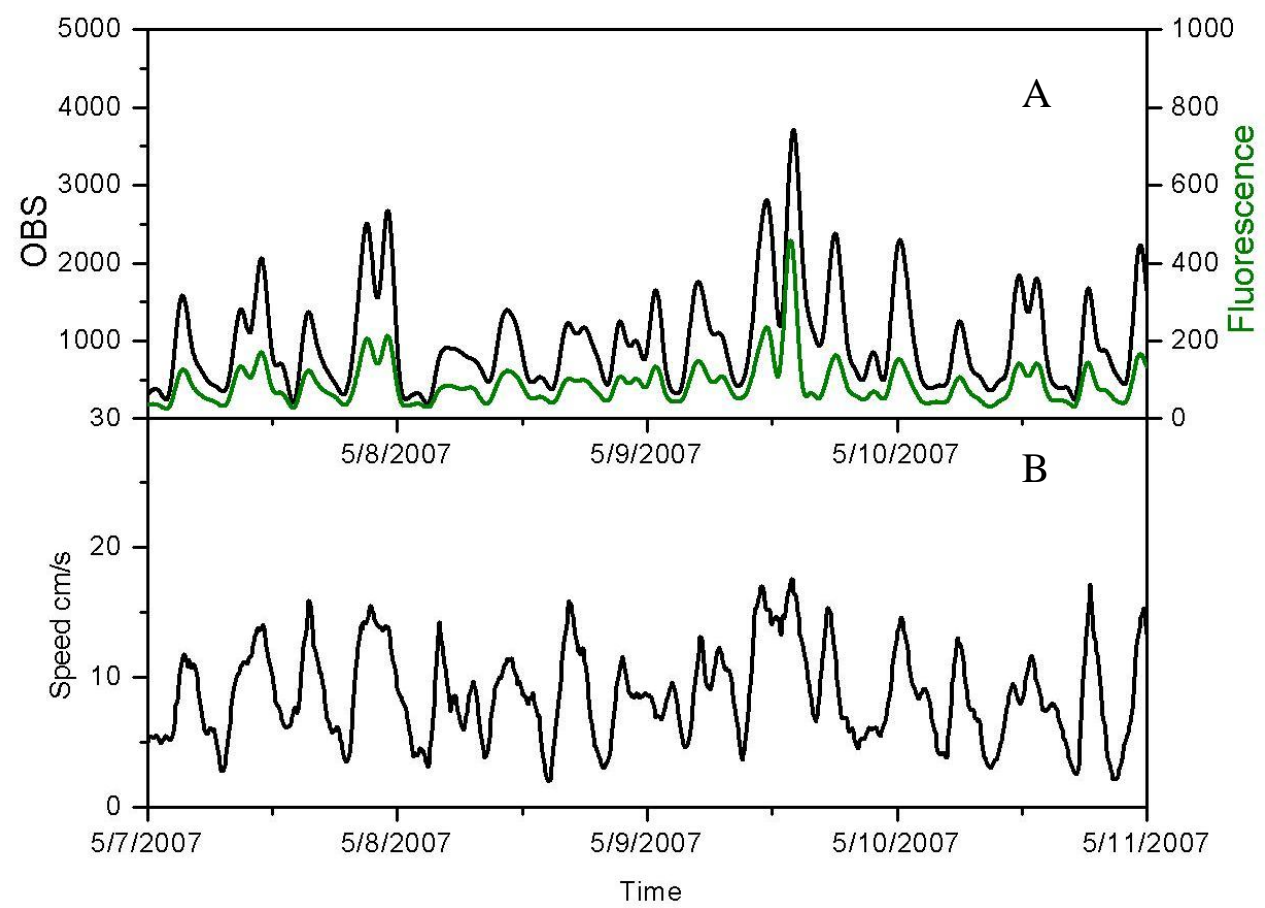

Figure 8 

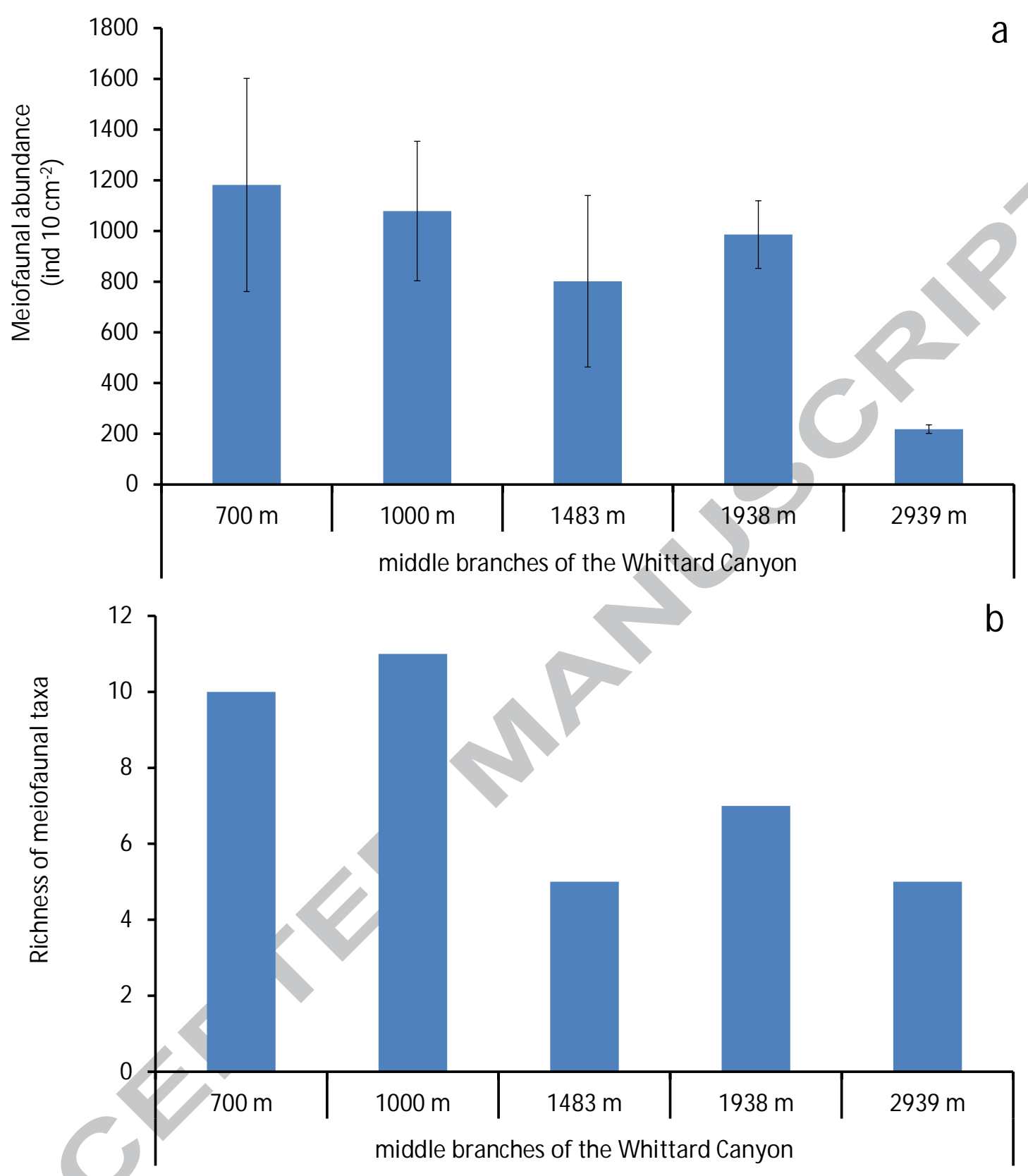

Figure 9 

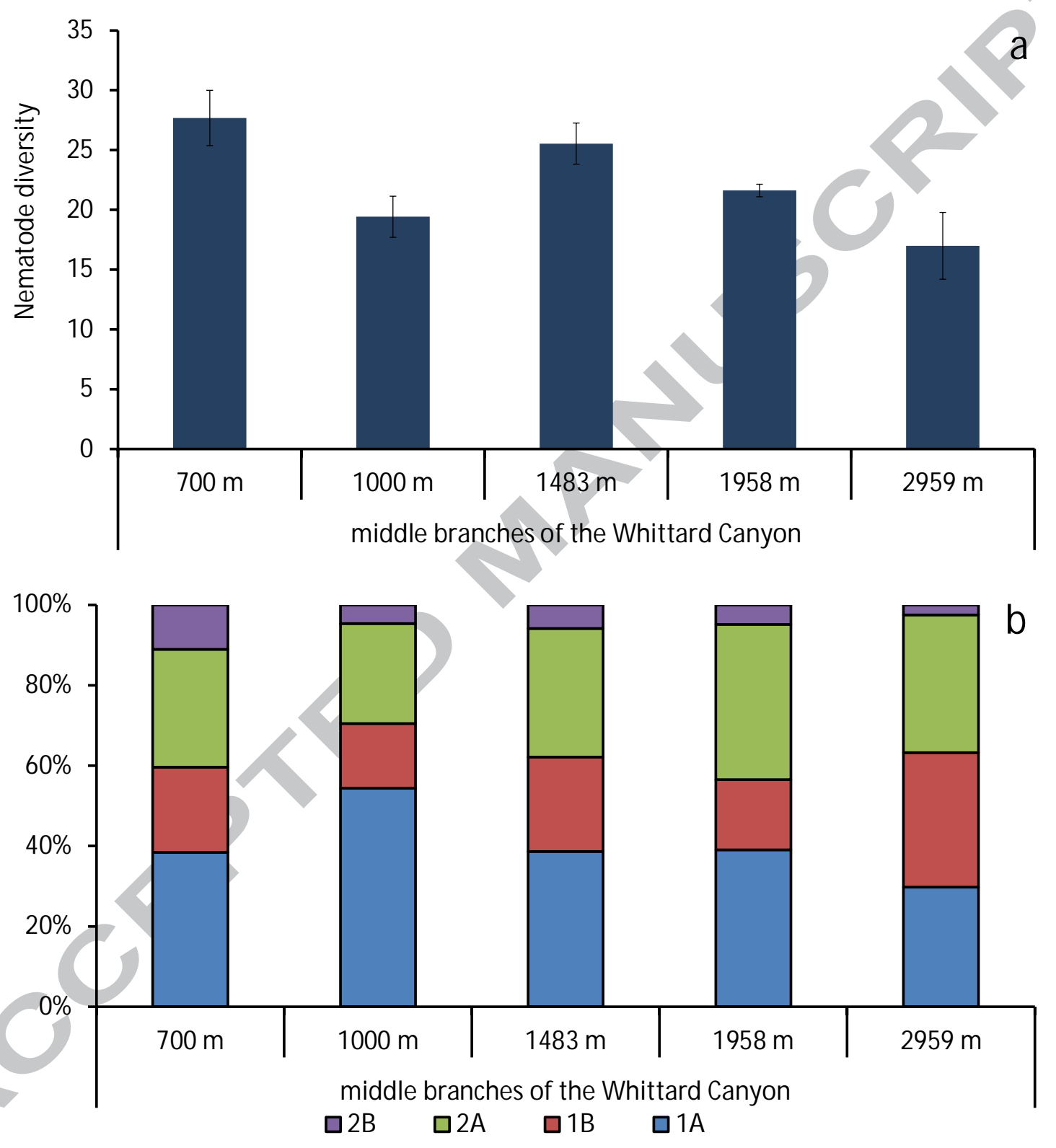

Figure 10 


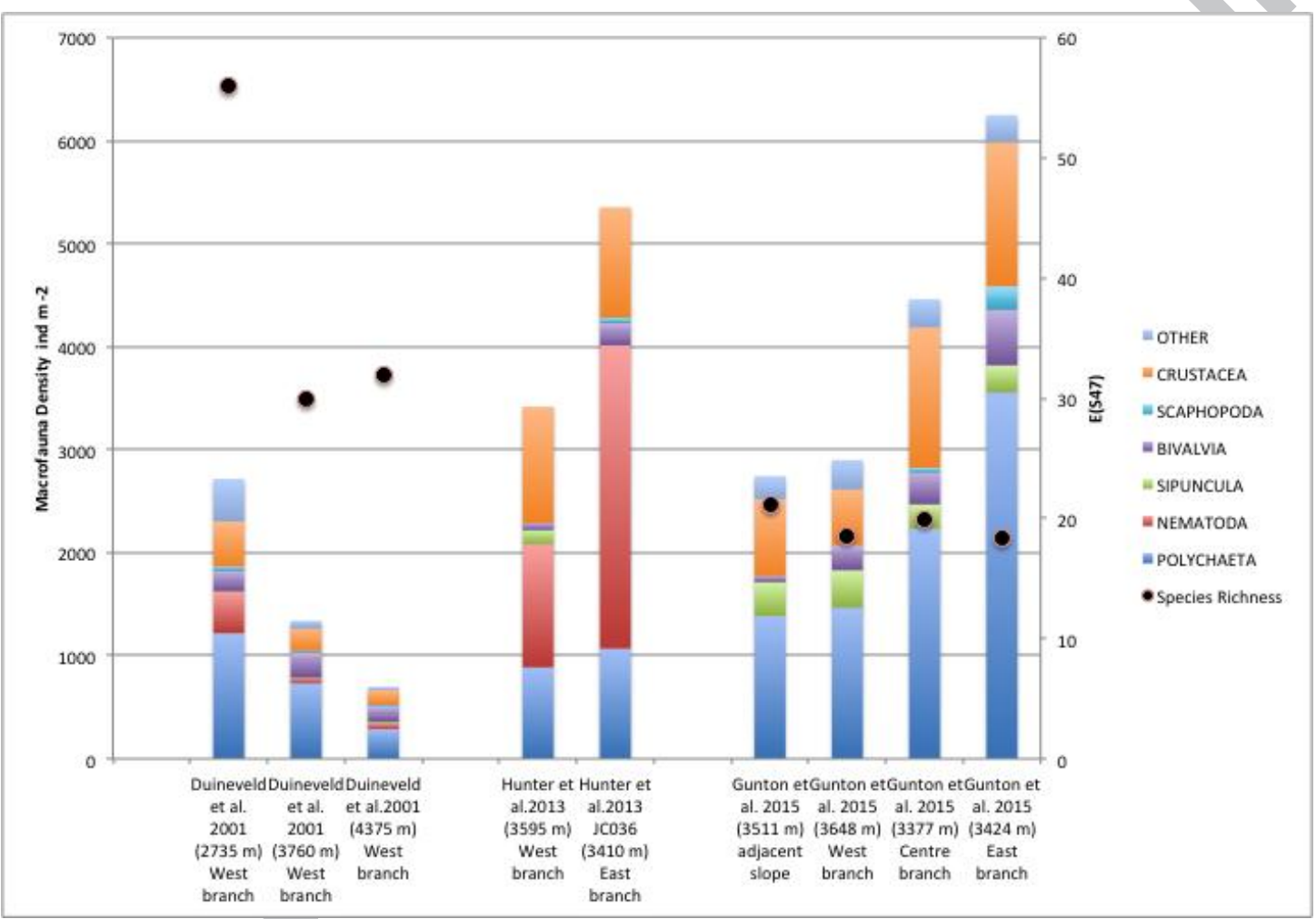

Figure 11 
Table 1 Datasets and published papers used as input for this overview paper. Sample locations are represented in Fig. 1c. Canyon branch: WC, Whittard Channel; W, western branch; WM, western middle branch; EM, eastern middle branch; E, eastern branch; S, open slope next to the canyon.

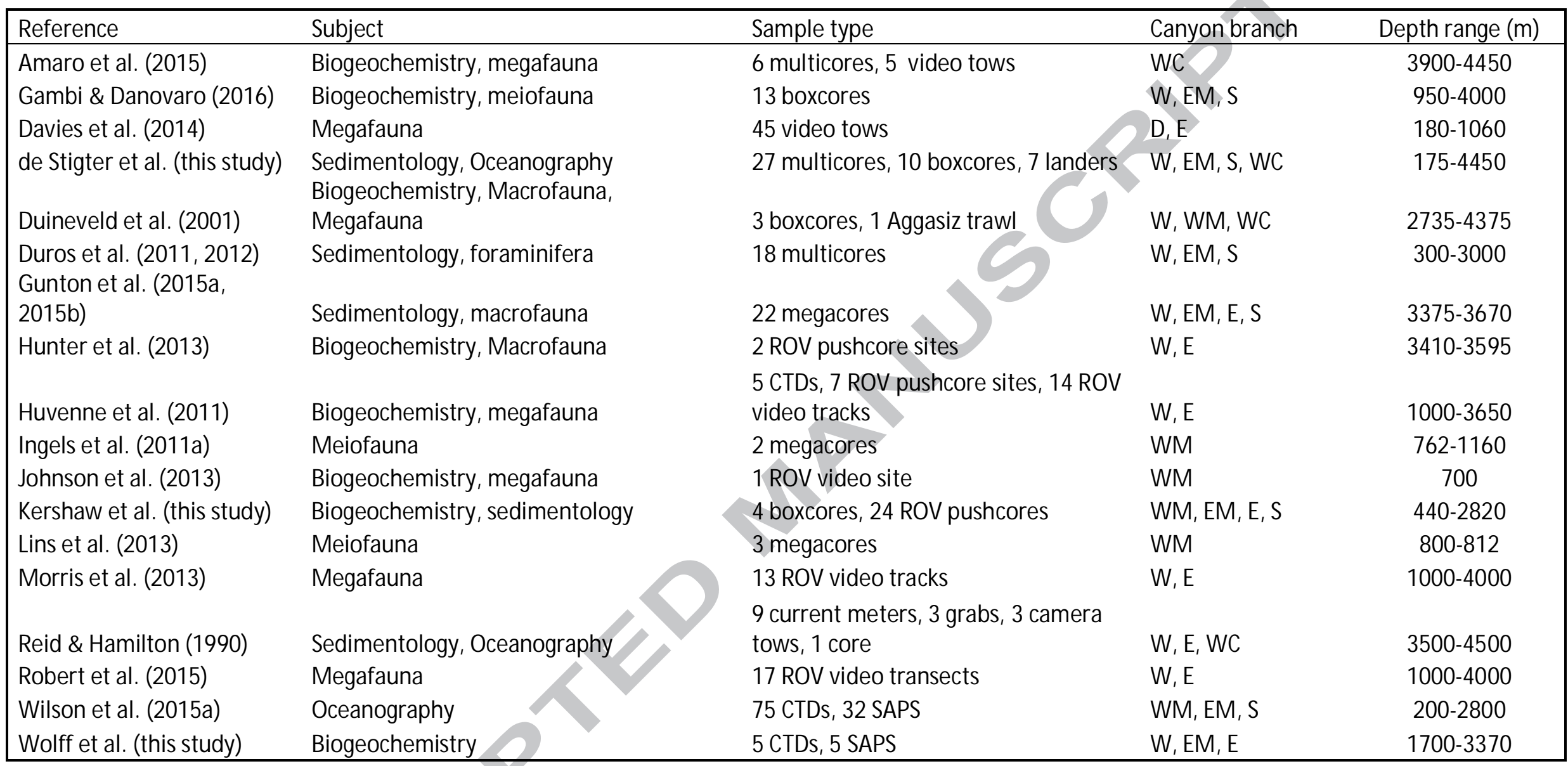




\section{Highlights}

The Whittard Canyon is an active system in terms of sediment transport.

The net suspended sediment transport is mainly up-canyon, but occasionally sediment gravity flow events do occur. However, their role in transferring labile organic matter to the deeper regions of the canyon appears to be limited. The fresh OM found in deeper regions (Whittard Channel) appears to arrive through the vertical deposition and lateral transport of settling phytodetritus from phytoplankton blooms that occur during spring and summer.

Foraminiferal abundances are higher in the upper parts of the canyon and on the slope than in the lower canyon.

Meiofaunal abundances in the upper and middle part of the canyon are higher than on adjacent slopes, but lower in the deepest part. Nematode diversity at genus level decreased progressively with increasing water depth in the western middle branch of the Whittard Canyon; this was not the case for meiofauna higher taxa diversity.

Macrofauna abundances are higher in the canyon compared with the adjacent slope and are higher in the eastern than the western branch. Macrofaunal diversity appeared to be depressed inside the Whittard Canyon compared to the adjacent slope. 
Megafauna abundances are higher in the canyon compared with the adjacent slope and are higher in the eastern than the western branch. Megafauna diversity increased on steep slopes and topographic highs and decreased towards the thalweg.

These faunal patterns reflect the fact that the Whittard Canyon encompasses considerable environmental heterogeneity, related to a combination of organic matter trapping, current regimes (due to focused internal tides) and different substrates. 